\title{
Article \\ Cu-Catalyzed Hydrodehalogenation of Brominated Aromatic Pollutants in Aqueous Solution
}

\author{
Tomáš Weidlich ${ }^{1, *}$, Barbora Kamenická ${ }^{1}$, Ludvík Beneš ${ }^{2}$, Veronika Čičmancová ${ }^{3}$, Alena Komersová ${ }^{4}$ (D), \\ Jiří Čermák ${ }^{5}$ and Petr Švec ${ }^{6}$
}

1 Chemical Technology Group, Faculty of Chemical Technology, Institute of Environmental and Chemical Engineering, University of Pardubice, Studentská 573, 53210 Pardubice, Czech Republic; barbora.kamenicka@student.upce.cz

2 Joint Laboratory of Solid State Chemistry, Faculty of Chemical Technology, University of Pardubice, Studentská 84, 53210 Pardubice, Czech Republic; ludvik.benes@upce.cz

3 Center of Materials and Nanotechnologies, Faculty of Chemical Technology, University of Pardubice, Nám. Čs. Legií 565, 53002 Pardubice, Czech Republic; veronika.cicmancova@upce.cz

4 Department of Physical Chemistry, Faculty of Chemical Technology, University of Pardubice, Studentská 573, 53210 Pardubice, Czech Republic; alena.komersova@upce.cz

5 VUOS, a. s.-Research Institute for Organic Syntheses, č.p. 296, 53354 Rybitví, Czech Republic; jiri.cermak@vuos.com

6 Department of General and Inorganic Chemistry, Faculty of Chemical Technology, University of Pardubice, Studentská 573, 53210 Pardubice, Czech Republic; petr.svec2@upce.cz

* Correspondence: tomas.weidlich@upce.cz; Tel.: +420-46-603-8049

Citation: Weidlich, T.; Kamenická, B.; Beneš, L.; Čičmancová, V.;

Komersová, A.; Čermák, J.; Švec, P. Cu-Catalyzed Hydrodehalogenation of Brominated Aromatic Pollutants in Aqueous Solution. Catalysts 2021, 11, 699. https://doi.org/10.3390/ catal11060699

Academic Editor: Sonia Carabineiro

Received: 14 April 2021

Accepted: 26 May 2021

Published: 31 May 2021

Publisher's Note: MDPI stays neutral with regard to jurisdictional claims in published maps and institutional affiliations.

Copyright: (c) 2021 by the authors. Licensee MDPI, Basel, Switzerland. This article is an open access article distributed under the terms and conditions of the Creative Commons Attribution (CC BY) license (https:// creativecommons.org/licenses/by/ $4.0 /)$.
Abstract: The catalytic effect of copper in Devarda's Al-Cu-Zn alloy (Dev. alloy) and sole metallic copper, copper salts and copper oxides in the coaction of $\mathrm{NaBH}_{4}$ within the hydrodehalogenation (HDH) of polybrominated phenols, such as the herbicide Bromoxynil in alkaline aqueous solution has been investigated. Namely, the hydrodebromination (HDB) activity of Dev. alloy/NaOH system has been compared to heterogeneous $\mathrm{Cu}$-based catalysts using $\mathrm{NaBH}_{4}$ as a reductant. Differences in the solid-state structures of used $\mathrm{Cu}$-based heterogeneous catalysts after the mentioned HDB process have been studied using the powder XRD and SEM techniques. It was found that some of the used copper-based catalysts are reusable and reasonably effective even at room temperature. Efficiency of the most promising copper-based reduction systems (Dev. alloy/ $\mathrm{NaOH}$ and Cu-based catalysts $/ \mathrm{NaBH}_{4}$ ) have been successfully tested within the HDB of industrially important brominated flame retardant tetrabromobisphenol A (TBBPA). Dev. alloy/ $\mathrm{NaOH}$ and $\mathrm{Cu}$-based catalyst generated in-situ within the $\mathrm{CuSO}_{4} / \mathrm{NaBH}_{4}$ produced were recognized as the most active HDB agents for complete debromination of both BRX and TBBPA.

Keywords: Hydrodebromination; bromophenol; copper; Devarda's Al-Cu-Zn alloy; cuprous oxide; cupric oxide; $\mathrm{NaBH}_{4}$; dehalogenation; Bromoxynil; TBBPA

\section{Introduction}

Copper and its salts exhibit broad catalytic activity mainly due to the easily accessible and reasonable stability of $\mathrm{Cu}(0), \mathrm{Cu}(\mathrm{I})$ and $\mathrm{Cu}(\mathrm{II})$ oxidation states [1-5]. They are therefore effective catalysts for both $\mathrm{C}_{\text {arom }}-\mathrm{H}$ bonds transformations [1,2] and $\mathrm{C}_{\text {arom }}$-halogen cleavage reactions $[3,4]$.

Hydrodebromination (HDB) involves hydrogenolysis of C-Br bonds, requires an external supply of reductant (usually a source of hydrogen) and is typically promoted using a metal catalyst [4,5].

Brominated aromatic compounds have been broadly used mainly as effective flame retardants [6] and as pesticides [7]. The widespread application of such species has raised concerns about their persistence in the environment and their potential toxic effects on non-target organisms, including humans $[8,9]$. 
Bromoxynil (BRX) is a brominated hydroxybenzonitrile-based selective contact foliage herbicide used to control a variety of broadleaf weeds. In the past several years, bromoxynil has been applied in increasing quantities as a possible replacement for atrazine, which has been banned in many countries [10]. BRX has been classified as a Group C possible human carcinogen, and has been shown to be an endocrine disrupter in birds, fish and aquatic invertebrates. BRX can be present in soil, as well as surface water and contaminated ground waters by runoff and leaching [11,12]. In water, it is likely to pose health hazards to non-target aquatic organisms. Even the acute pesticide poisoning by bromoxynil was reported [13].

Tetrabromobisphenol A (TBBPA) has been widely used as brominated flame retardant (BFRs) in printed circuit boards, insulated wires and various polycarbonate plastics owing to its fire-resistant properties [13]. Due to the structural similarity of TBBPA with thyroid hormones, its release into the surroundings threatens the safety and health of the ecosystem, terrestrial and aquatic animals, and human health. The worldwide application releases TBBPA from the manufacturing, consumer product uses, recycling, and disposal process into the surrounding environment. So far, TBBPA and other BFRs pollutants have been detected in various environmental matrices including water [14].

Following toxicity of the mentioned brominated phenols and its increasing application, studying its effective degradation to the readily biodegradable products is desired. In most cases, oxidation processes are used for chemical treatment of recalcitrant contaminants [15-20].

However, especially ortho-halogenated phenols tend to be transformed to the significantly more toxic dibenzo-p-dioxines using some oxidation processes [5,21]. It was published that photochemical $\mathrm{H}$-atom abstraction from the $\mathrm{OH}$ group of $\mathrm{BRX}$ results in the formation of unstable phenoxy radical, which can undergo self-reaction resulting in the formation of brominated dibenzo-p-dioxins [21].

These brominated compounds are considered as the most dangerous persistent organic pollutants (POP) [22]. Due to the aforementioned reasons, the reductive treatment to non-halogenated and readily biodegradable products has recently gained attention [14,23-25]. Cu-catalyzed or Cu-mediated reductive treatment via the HDB plays important role in detoxification of polybrominated aromatic contaminants, as was previously published [26-30].

In this study, our primary objectives were to; (1) test the reaction conditions (minimal excess of reagents) necessary for the complete Cu-mediated HDB of BRX in alkaline aqueous solution, including the possibility of used/spent $\mathrm{Cu}$-catalyst recycling, (2) compare effect of metallic copper, different copper alloys and copper compounds on the HDB efficiency of BRX, and finally (3) apply and compare studied reaction conditions for the possible HDB of TBBPA.

\section{Results and Discussion}

A set of experiments, involving chemically diverse reductants within the HDB of 3,5-dibromo-4-hydroxybenzonitrile (BRX), and dissolved in alkaline aqueous solution, were performed. Electropositive metals, various copper alloys containing electropositive metals and $\mathrm{NaBH}_{4}$ were employed as potential HDB agents in these experiments. The results summarized in Table 1 show that only the Dev. alloy exhibits high HDB activity at room temperature over one hundred minutes of vigorous stirring of the respective reaction mixture (Table 1, Entries 1-8, Schemes 1 and 2, Figures 1 and 2). Other employed copper alloys are not effective within the HDB of BRX even at elevated temperature under such basic conditions (Table 1, Entries 9-11). Powdered aluminium, $\mathrm{Fe}_{3} \mathrm{Al}$ alloy or zinc without coaction of copper exhibited no HDB efficiency towards BRX (Entries 12-15). Similarly, BRX is inert toward action of powdered elemental copper and other tested copper compounds without added reductant (Supplementary Materials Table S1). As expected, sole sodium borohydride causes mostly only partial HDB of BRX without addition of copper, even at elevated temperatures (Table 1, Entries 16 and 17). Upon the addition of metallic copper 
to $\mathrm{NaBH}_{4}$, complete conversion of $\mathrm{BRX}$ is accomplished under comparable conditions (Table S2, Entries 5-7). The quantitative HDB of BRX is observed at elevated temperature (Table S2, Entry 5). These findings are in the agreement with our previous results regarding the HDB of 2,4,6-tribromophenol [26].

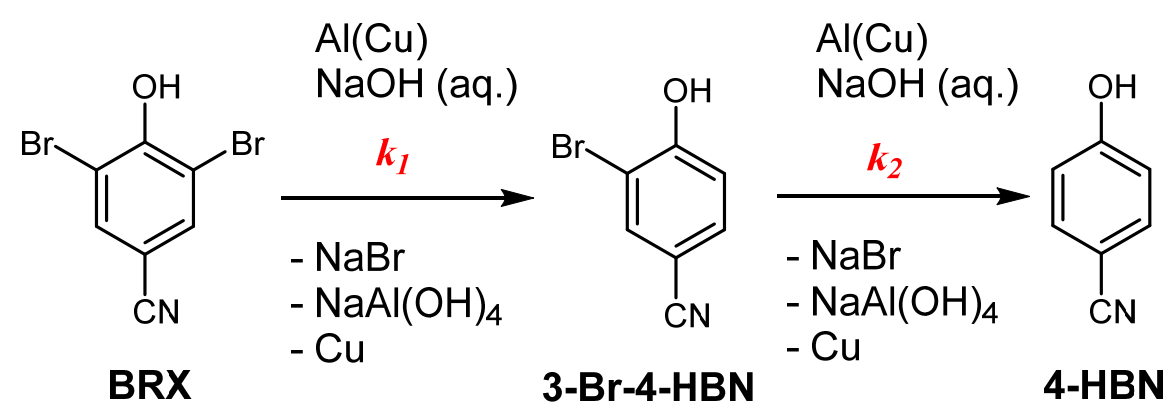

Scheme 1. Total HDB of BRX using the Dev. alloy in aqueous $\mathrm{NaOH}$ proceeding via the 3-bromo-4hydroxybenzonitrile (3-Br-4-HBN).

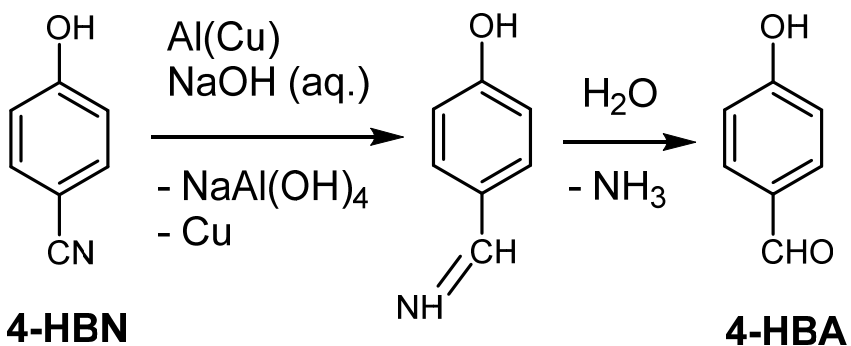

Scheme 2. Reduction of the cyano group in 4-HBN using the Dev. alloy in aqueous $\mathrm{NaOH}$.

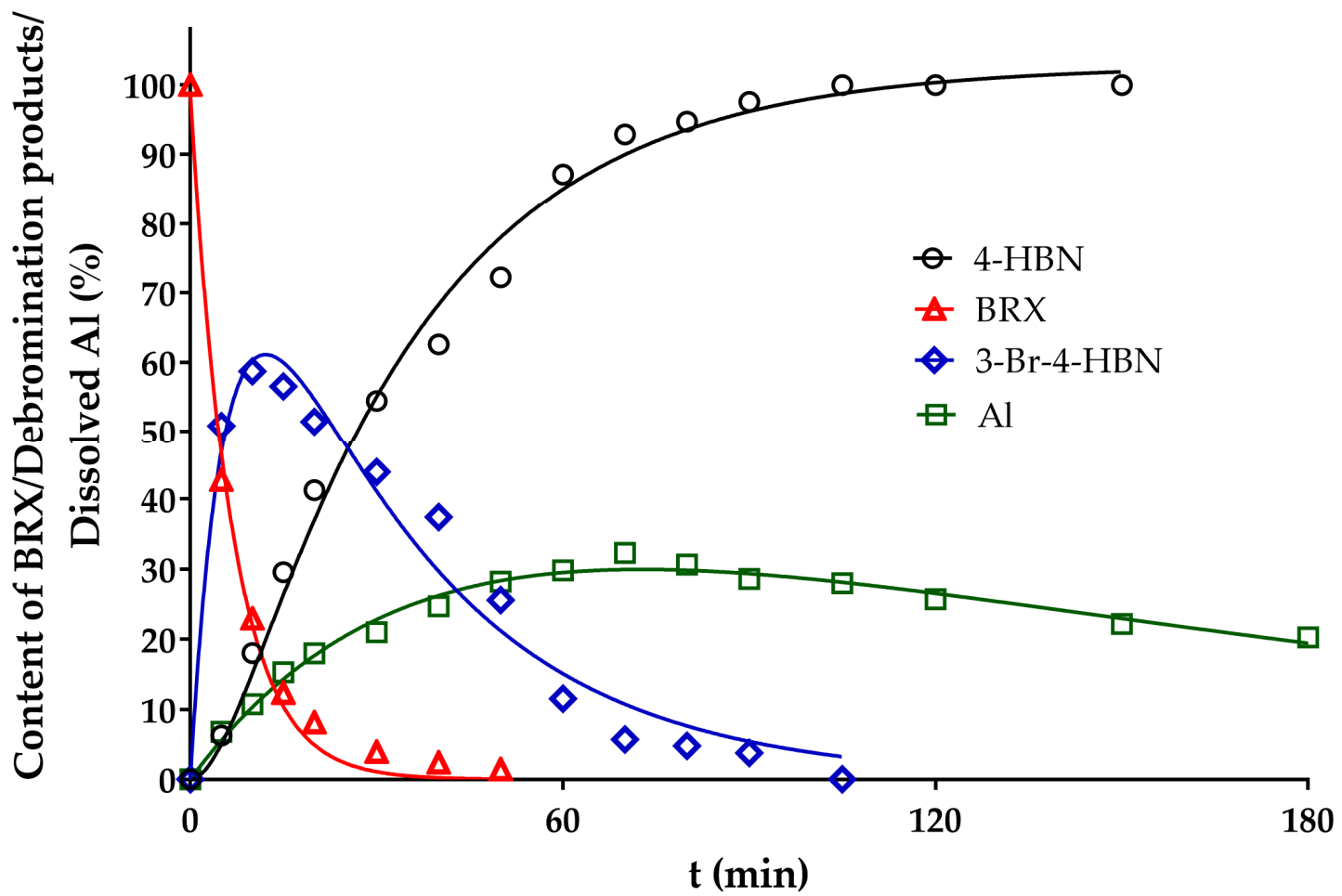

Figure 1. Kinetics of the HDB of BRX ( $5 \mathrm{mM})$ in $100 \mathrm{mM}$ aq. $\mathrm{NaOH}$ using Dev. alloy $(3 \mathrm{~g} / \mathrm{L})$. In addition, the percentage of soluble part of $\mathrm{Al}$ from original Dev. alloy is supplemented. 
Table 1. Efficiencies of different electropositive metals, their alloys and $\mathrm{NaBH}_{4}$ on the $\mathrm{HDB}$ of BRX.

\begin{tabular}{|c|c|c|c|c|c|c|c|c|c|c|}
\hline \multirow{2}{*}{ Entry No. } & \multirow{2}{*}{$\begin{array}{l}\text { Reduction Agent Used } \\
\text { in aq. Sol of BRX }\end{array}$} & \multirow{2}{*}{$\begin{array}{l}\text { NaOH Conc. } \\
\text { (mmol) }\end{array}$} & \multirow{2}{*}{ Temperature } & \multirow{2}{*}{$\begin{array}{l}\text { Reaction } \\
\text { Time }\end{array}$} & \multicolumn{4}{|c|}{ Content of Phenolic Compounds (\%) } & \multirow{2}{*}{$\begin{array}{c}\text { Content of } \\
\text { Dissolved Al (g/L) }\end{array}$} & \multirow{2}{*}{$\begin{array}{l}\text { Insoluble } \\
\text { Matter (g) }\end{array}$} \\
\hline & & & & & BRX & 4-HBN & 4-HBA & 3-Br-4-HBN & & \\
\hline 1 & $0.6 \mathrm{~g}$ Dev. alloy & 10 & R.T. & overnight & - & 57.9 & 42.1 & - & 1.565 & 0.3 \\
\hline 2 & $0.6 \mathrm{~g}$ Dev. alloy & 10 & R.T. & $66 \mathrm{~h}$ & - & 64.5 & 35.5 & - & 1.103 & 0.36 \\
\hline 3 & $0.4 \mathrm{~g}$ Dev. alloy & 10 & R.T. & $66 \mathrm{~h}$ & - & 80 & 20 & - & 1.525 & 0.14 \\
\hline 4 & $0.4 \mathrm{~g}$ Dev. alloy & 20 & R.T. & overnight & - & 87.7 & 12.3 & - & 1.561 & 0.21 \\
\hline 5 & $0.5 \mathrm{~g}$ Dev. alloy & 10 & R.T. & overnight & - & 100 & - & - & 0.671 & 0.41 \\
\hline 6 & $0.3 \mathrm{~g}$ Dev. alloy & 10 & R.T. & $150 \mathrm{~min}$. & - & 100 & - & - & 0.794 & 0.22 \\
\hline 7 & $0.25 \mathrm{~g}$ Dev. alloy & 10 & R.T. & overnight & - & 100 & - & - & n.d. & n.d. \\
\hline 8 & $0.3 \mathrm{~g}$ Dev. alloy & 2 & R.T. & $180 \mathrm{~min}$. & 5.3 & 34.9 & - & 59.8 & n.d. & n.d. \\
\hline 9 & $1 \mathrm{~g} \mathrm{Cu}-\mathrm{Zn}$ alloy & 10 & $\begin{array}{l}1 \mathrm{~h} \text { at } 70^{\circ} \mathrm{C}+ \\
92 \mathrm{~h} \text { at R.T. }\end{array}$ & $93 \mathrm{~h}$ & 100 & - & - & - & - & n.d. \\
\hline 10 & $\begin{array}{c}0.91 \mathrm{~g} \text { silver brazing alloy } \\
\text { Ag:Cu:Zn }\end{array}$ & 10 & $\begin{array}{l}1 \mathrm{~h} \text { at } 70^{\circ} \mathrm{C}+ \\
92 \mathrm{~h} \text { at R.T. }\end{array}$ & $93 \mathrm{~h}$ & 100 & - & - & - & - & n.d. \\
\hline 11 & $0.7 \mathrm{~g} \mathrm{Cu}-S n$ alloy & 10 & $\begin{array}{c}1 \mathrm{~h} \text { at } 70^{\circ} \mathrm{C}+ \\
92 \mathrm{~h} \text { at R.T. }\end{array}$ & $93 \mathrm{~h}$ & 100 & - & - & - & - & n.d. \\
\hline 12 & $1 \mathrm{~g} \mathrm{Fe}_{3} \mathrm{Al}$ alloy & 10 & R.T. & overnight & 100 & - & - & - & n.d. & n.d. \\
\hline 15 & $0.5 \mathrm{~g} \mathrm{Zn}$ & 10 & R.T. & overnight & 100 & - & - & - & - & n.d. \\
\hline 16 & $0.8 \mathrm{~g} \mathrm{NaBH}_{4}$ & 10 & R.T. & $96 \mathrm{~h}$ & 100 & - & - & - & - & 0 \\
\hline 17 & $0.4 \mathrm{~g} \mathrm{NaBH}_{4}$ & 10 & $\begin{array}{c}1 \mathrm{~h} \text { at } 70^{\circ} \mathrm{C}+92 \\
\text { h at R.T. }\end{array}$ & $93 \mathrm{~h}$ & - & 6.4 & - & 93.6 & - & 0 \\
\hline
\end{tabular}

${ }^{1} 0.5 \mathrm{mmol}$ of $\mathrm{BRX}$ dissolved in $100 \mathrm{~mL}$ of aqueous $\mathrm{NaOH}$ with specified concentration. R.T. $=$ room temperature. n.d.= not determined. 


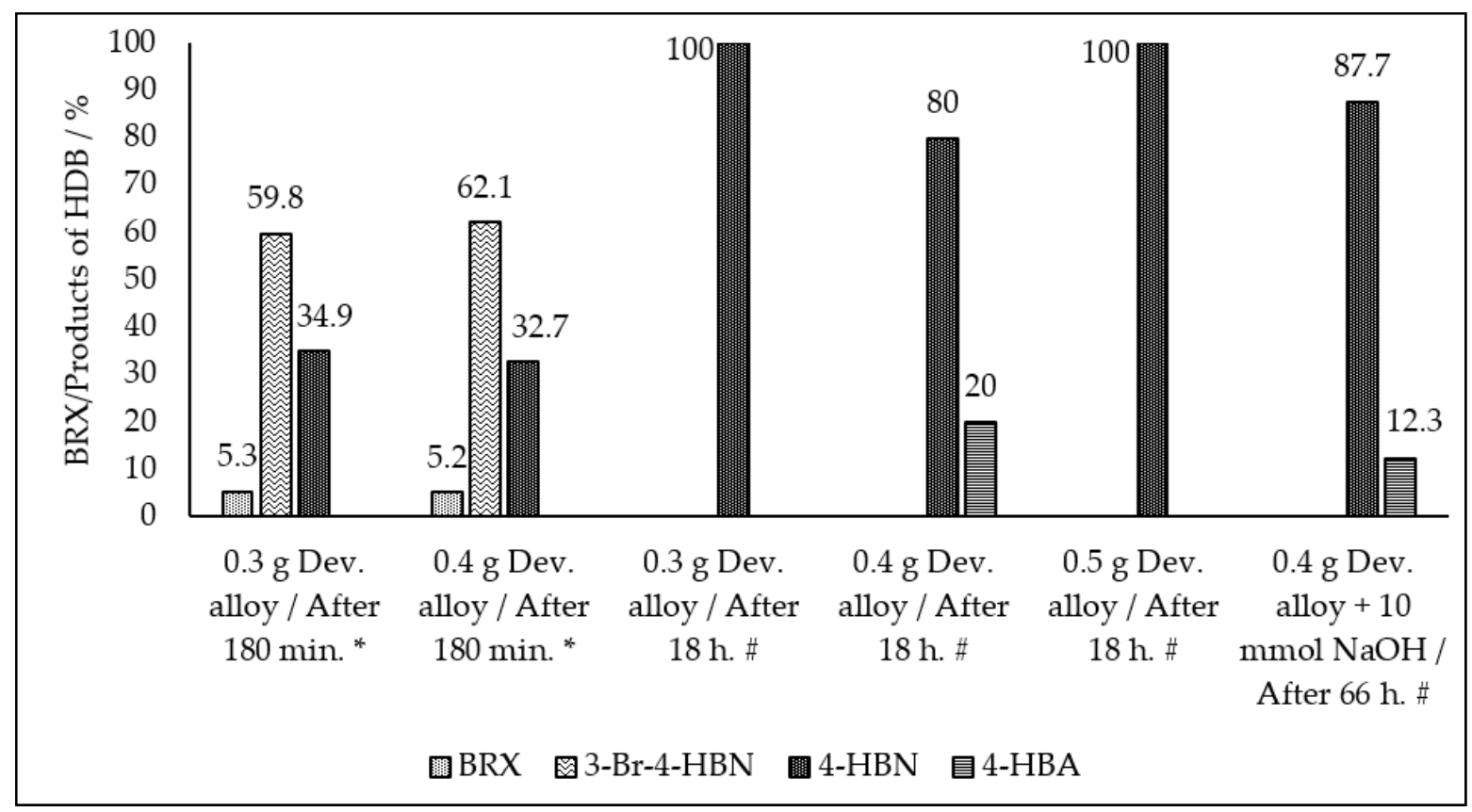

Figure 2. $\mathrm{HDB}$ of BRX using appropriate amount of Dev. alloy and $\mathrm{NaOH}$. Dev. alloy was added to the solution containing $0.5 \mathrm{mmol} \mathrm{BRX}+2 \mathrm{mmol} \mathrm{NaOH}$ in $100 \mathrm{~mL} \mathrm{H}_{2} \mathrm{O}\left({ }^{*}\right)$; or $0.5 \mathrm{mmol} \mathrm{BRX}+10 \mathrm{mmol} \mathrm{NaOH}$ in $100 \mathrm{~mL} \mathrm{H}_{2} \mathrm{O}$ (\#).

Except the above mentioned superior HDB activity of the Dev. alloy towards BRX, formation of 4-hydroxybenzaldehyde (4-HBA) generated by a reduction of the cyano group (Scheme 2) was observed in the case of prolonged reaction times and/or use of a higher excess of the Dev. alloy (Table 1, Entries 1-4). Such C $\equiv N$ moiety reduction using a nickel-based catalyst [31] or aluminium hydrides under strictly anhydrous conditions has been already reported [32]. To the best of our knowledge, no Cu-catalyzed cyanogroup reductions in aqueous solutions at ambient temperatures have been published in the literature.

The reaction rate of the Dev. alloy-mediated HDB of BRX has been studied using $3 \mathrm{~g}$ of the Dev. alloy per liter of $5 \mathrm{mM}$ of $\mathrm{BRX}$ in $100 \mathrm{mM} \mathrm{NaOH}$ aqueous solution (Figure 1). The quantity (wt. \%) of dissolved $\mathrm{Al}$ from the original Dev. Alloy is depicted in Figure 1, too. The complete HDB of BRX along with the presence of brominated by-product 3-Br-4-HBN was observed after ca. $120 \mathrm{~min}$ at room temperature under vigorous stirring. Unfortunately, however, the minimal quantity of the Dev. alloy for exhaustive HDB of $1 \mathrm{~mol}$ of BRX dissolved in 20-fold molar excess of $0.4 \mathrm{wt} . \% \mathrm{NaOH}$ was $0.5 \mathrm{~kg} / \mathrm{mol}$ (or $250 \mathrm{~g}$ Dev. alloy per $1 \mathrm{~mol}$ of reduced C-Br bonds, calculated from exp. Table 1, Entry 7).

Although the overall amount of the Dev. alloy required for complete HDB of BRX could be probably further optimized, the question of circular economy of the studied Dev. alloy based HDB process arises. Spent aluminium and zinc metals are almost completely removed in the form of its appropriate metal hydroxides from the subsequently neutralized reaction mixtures after the HDB process, which has been proven in the past $[5,26,33]$. These by-product hydroxides could be utilized as important components for cement production, eventually. Nevertheless, the amount of undissolved part of the spent Dev. alloy remained high and the used copper (which is mostly converted to $\mathrm{Cu}_{2} \mathrm{O}$ ) requires recycling for sustainability of this potential decontamination process.

The attempts to test recyclability of the used Dev. alloy (with already lower content of non-consumed aluminium) have been carried out. The starting Dev. alloy and its reaction products were identified by the X-ray powder diffraction (see Figures $3-5$ ) and ${ }^{1} \mathrm{H}$ NMR spectroscopy (Figure 6). The present crystalline phases were identified by comparison with 
standards in the PDF-4+ database [34,35]. For multiphase samples, the mass content of the individual components was calculated.

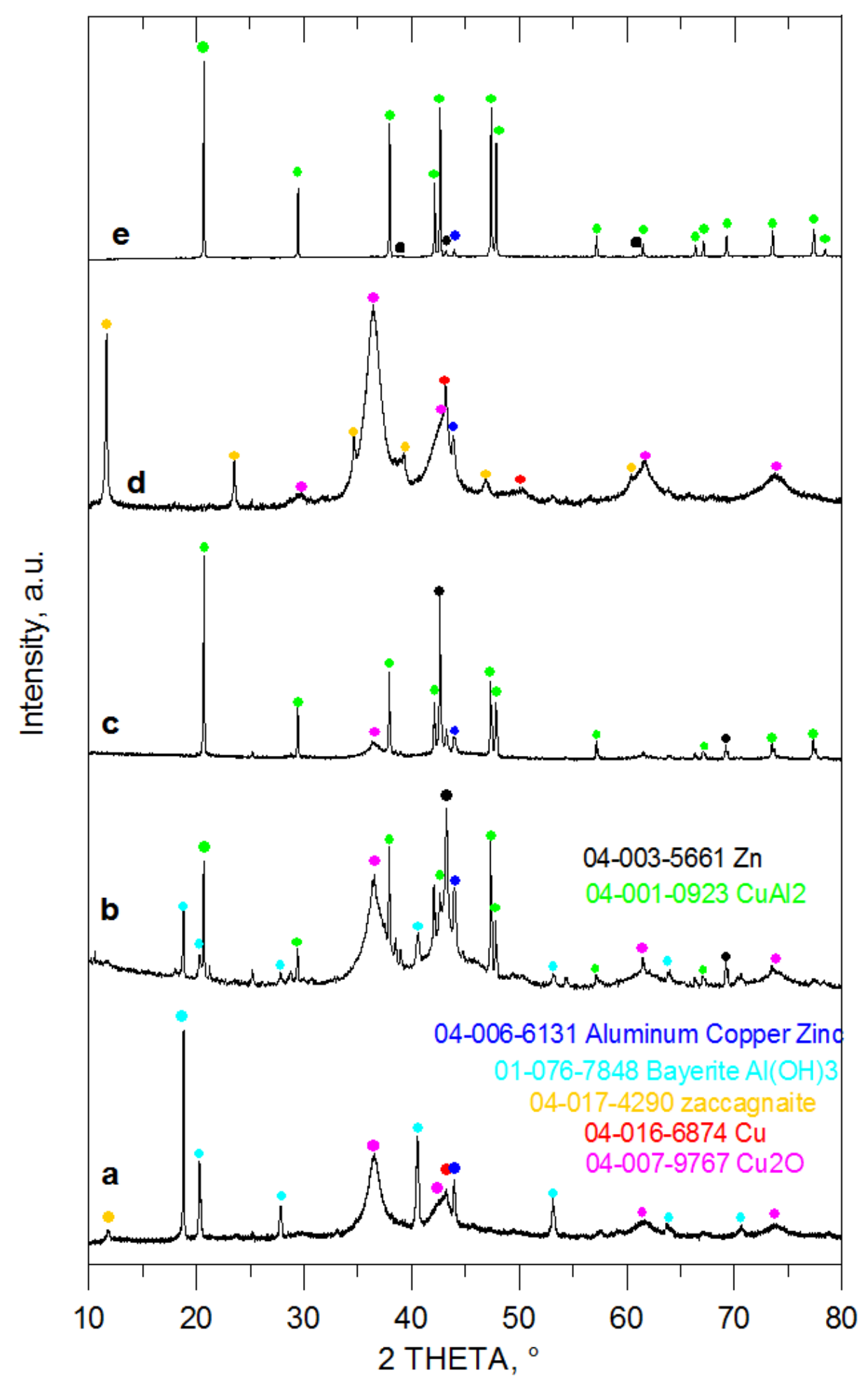

Figure 3. Powder $X$-ray diffractograms of undissolved residues obtained from different amounts of Dev. alloy used for the HDB of $5 \mathrm{mM}$ BRX dissolved in $100 \mathrm{mM}$ aqueous $\mathrm{NaOH}$ after $16 \mathrm{~h}$ of action ( $100 \%$ conversion to $4-\mathrm{HBN}$ in all cases): (a) $0.5 \mathrm{~g} / 100 \mathrm{~mL}$; (b) $0.6 \mathrm{~g} / 100 \mathrm{~mL}$; (c) $0.3 \mathrm{~g} / 100 \mathrm{~mL}$ $\left(+0.8 \mathrm{~g}\right.$ of $\left.\mathrm{NaBH}_{4}\right) ;($ d) $2.7 \mathrm{~g}$ of Dev. alloy after $180 \mathrm{~min}$. action $5 \mathrm{mM}$ BRX in $100 \mathrm{mM}$ aqueous. $\mathrm{NaOH}$ $(900 \mathrm{~mL})$ and after subsequent $16 \mathrm{~h}$ of action of $5 \mathrm{mM}$ BRX in $100 \mathrm{mM}$ aqueous $\mathrm{NaOH}(100 \mathrm{~mL})$. (e) starting Dev. alloy (predominantly contains $\mathrm{CuAl}_{2}$ ). 


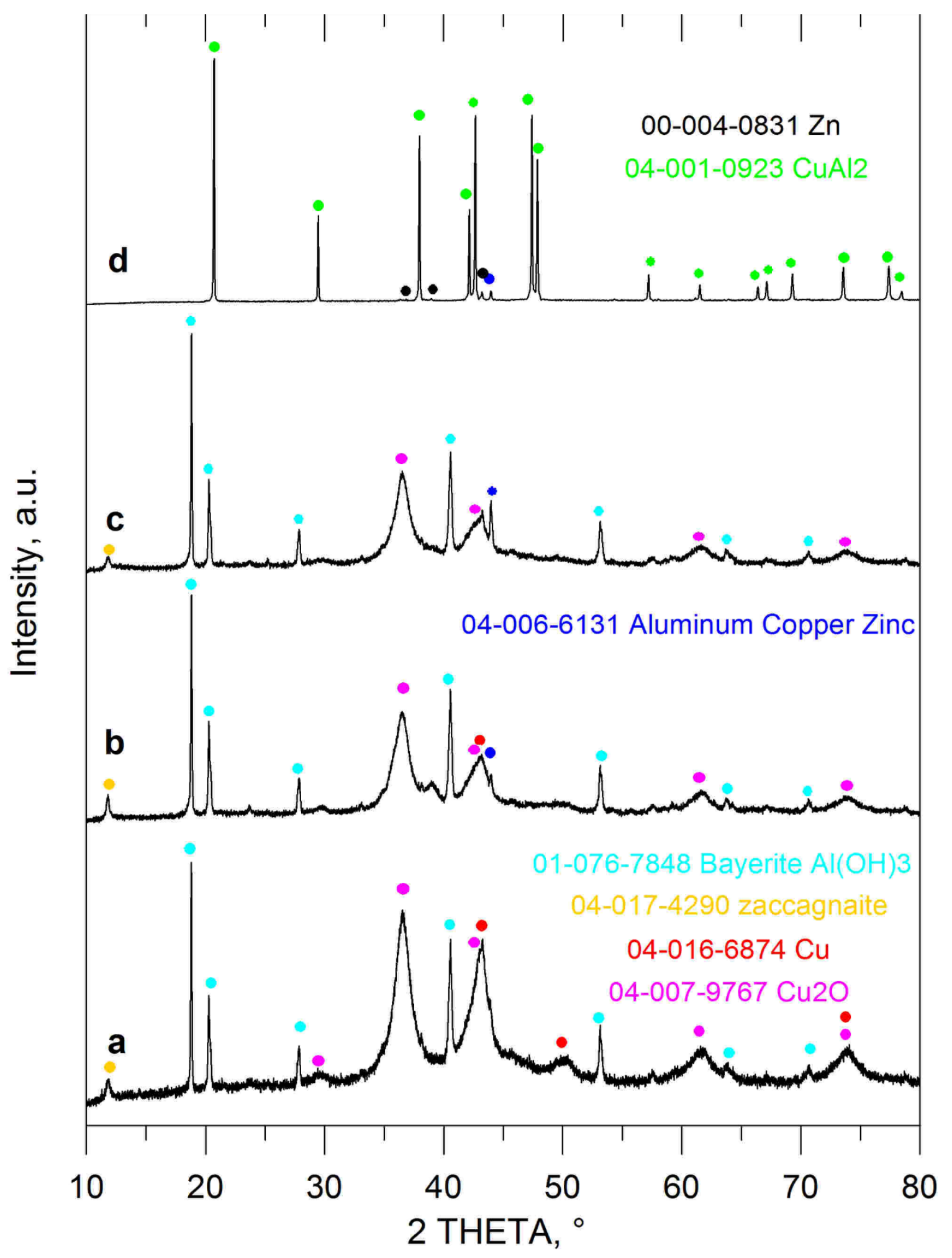

Figure 4. The comparison of powder X-ray diffractograms of Dev. alloy (d) unused; (c) used for overnight HDB of $5 \mathrm{mM}$ $\mathrm{BRX}$ in aq. $100 \mathrm{mM} \mathrm{NaOH}$; (b) recycled from step $c$ and subsequently used for overnight HDB of $5 \mathrm{mM} \mathrm{BRX} \mathrm{in} \mathrm{aq.} 100 \mathrm{mM}$ $\mathrm{NaOH}$ and coaction of $\mathrm{NaBH}_{4}$; (a) recycled from step $b$ and used for overnight reaction with $5 \mathrm{mM}$ BRX dissolved in $100 \mathrm{mM}$ $\mathrm{NaOH}$ and coaction of $\mathrm{NaBH}_{4}$. 

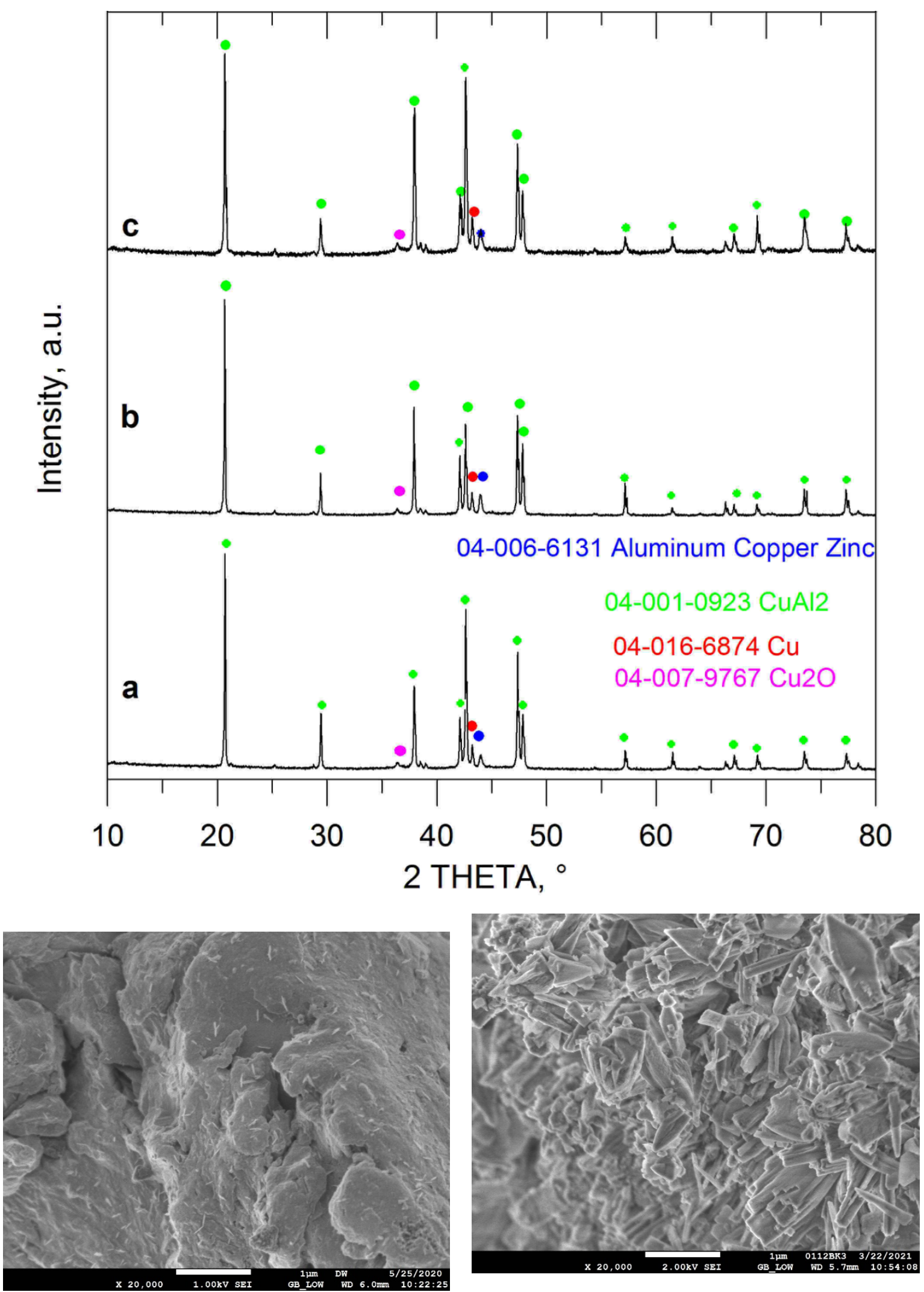

Figure 5. Powder X-ray diffractograms (top) of undissolved residue of Dev. alloy (0.7 g) after (a) 2 h; (b) 4 h and (c) 6 h of reaction with $5 \mathrm{mM}$ aq. BRX dissolved in $20 \mathrm{mM} \mathrm{NaOH}(100 \mathrm{~mL})$ and the coaction of $\mathrm{NaBH}_{4}(0.8 \mathrm{~g})$ and the SEM images of unused Dev. alloy (bottom left) and insoluble part of Dev. alloy after $6 \mathrm{~h}$ of reaction with $5 \mathrm{mM}$ aq. BRX dissolved in $20 \mathrm{mM} \mathrm{NaOH}(100 \mathrm{~mL})$ with coaction of $\mathrm{NaBH}_{4}(0.8 \mathrm{~g})$ (bottom right). 


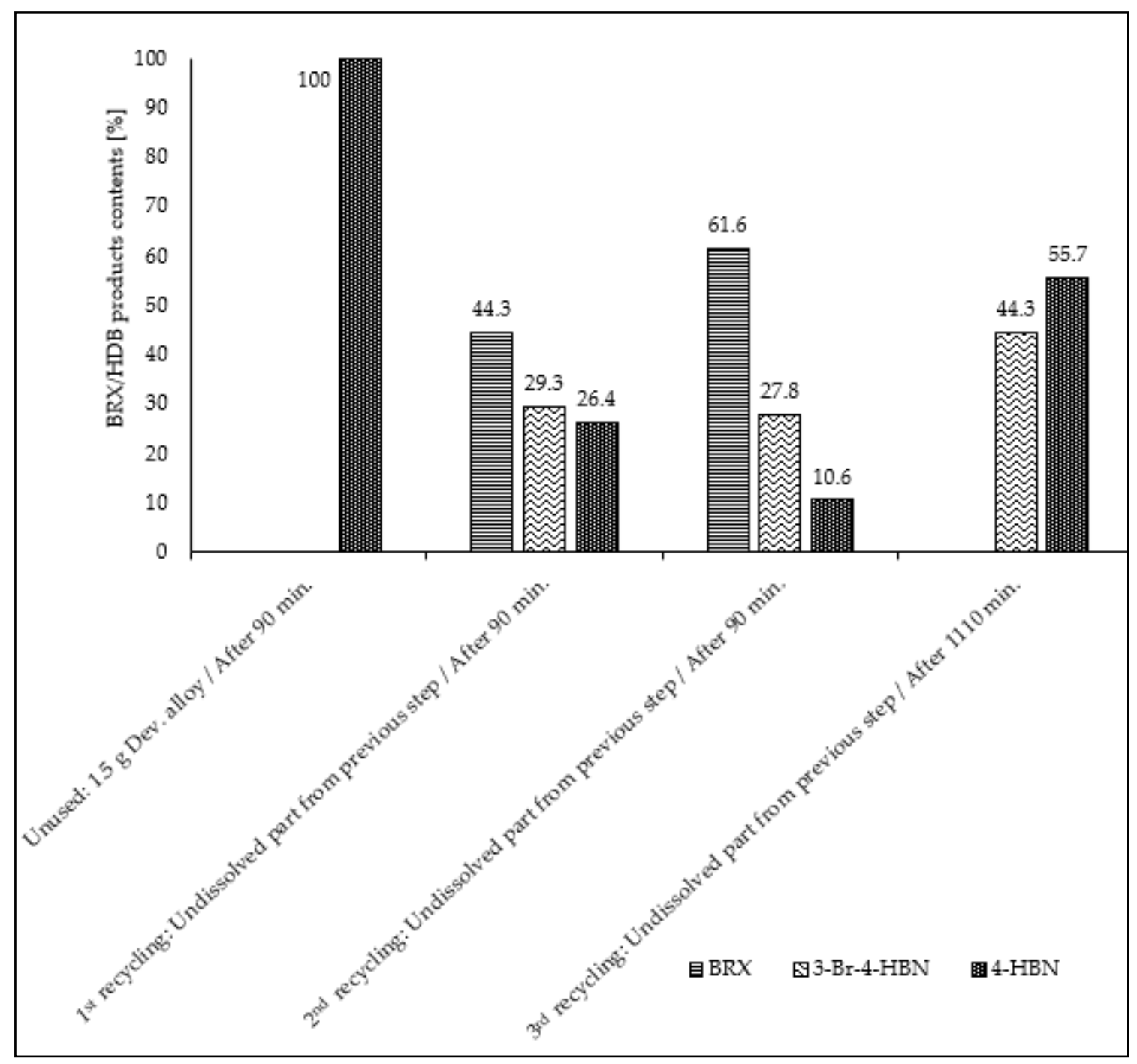

Figure 6. Comparison of HDB efficiencies involving unused and/or recycled Dev. alloy added to the solution of $2.5 \mathrm{mmol}$ $\mathrm{BRX}+50 \mathrm{mmol} \mathrm{NaOH}$ in $100 \mathrm{~mL} \mathrm{H}_{2} \mathrm{O}$.

Dev. alloy is composed of the mixture of khatyrkite $\mathrm{CuAl}_{2}$ as the main component (ca. 96\%) with crystallite size around 1000 Ångströms ( $\mathrm{A}$ ), zinc (ca. $2 \%$ with crystallite size ca. $680 \AA$ ) and aluminium-copper-zinc ternary system $\mathrm{Cu}_{1.14} \mathrm{Zn}_{0.20} \mathrm{Al}_{0.66}$ (ca. $2 \%$ and crystallite size ca. $530 \AA$ ) (Figure $4 \mathrm{~d}$ ).

The observed decrease in the activity of the used Dev. alloy within the HDB of $\mathrm{BRX}$ is presumably a consequence of a lack of remaining aluminium metal in the undissolved part of the Dev. Alloy, which is necessary for completion of the HDB process (Supplementary Materials Table S3).

As we described earlier [5], the Dev. alloy mixed with diluted $\mathrm{NaOH}$ solution is gradually converted to the aluminium hydroxide $\left(\mathrm{Al}(\mathrm{OH})_{3}\right)$, zaccagnaite (zinc aluminium carbonate hydroxide hydrate, $\left.\mathrm{Zn}_{4} \mathrm{Al}_{2}\left(\mathrm{CO}_{3}\right)(\mathrm{OH})_{12}\left(\mathrm{H}_{2} \mathrm{O}\right)_{3}\right)$ and cuprite $\left(\mathrm{Cu}_{2} \mathrm{O}\right)$ or even tenorite $(\mathrm{CuO})$, which is accompanied with hydrodehalogenation of some halogenated aromatic compounds occuring in aqueous solution. Oxidation of the original metals forming Dev. alloy is accompanied by significant changes on structure of this $\mathrm{Cu}$-based reductant, of course. Figure 3 compares changes in composition of different quantities of the Dev. alloy after $16 \mathrm{~h}$ of action on $5 \mathrm{mM}$ BRX in $100 \mathrm{mM}$ aqueous $\mathrm{NaOH}$ solution (complete HDB conversion was observed in all cases). Figure 3a,b illustrate undissolved residue obtained from $0.5 \mathrm{~g}$ (or $0.6 \mathrm{~g}$, respectively) of Dev. alloy in $100 \mathrm{~mL}$ of $5 \mathrm{mM}$ BRX dissolved in $100 \mathrm{mM}$ aqueous $\mathrm{NaOH}$ producing $42.1 \%$ of $4-\mathrm{HBA}$ and $57.9 \%$ of $4-\mathrm{HBN}$ as the 
HDB products (see Schemes 1 and 2). As evidenced by the powder X-ray diffractogram in Figure 3c, addition of $\mathrm{NaBH}_{4}$ to the Dev. alloy inhibits the corrosion of $\mathrm{Cu}-\mathrm{Al}$ significantly, and thus, no metallic $\mathrm{Cu}$ was observed in the undissolved residue after $16 \mathrm{~h}$ of action of $5 \mathrm{mM}$ BRX in $100 \mathrm{mM}$ aqueous $\mathrm{NaOH}$.

The powder XRD analysis of separated residue even after four-times used Dev. alloy identifies still ca. $8 \%$ of unreacted Al-Cu- $\mathrm{Zn}$ trimetallic alloy together with $85 \%$ of $\mathrm{Cu}_{2} \mathrm{O}$, $6 \%$ of elemental $\mathrm{Cu}$ and $1 \%$ of zaccagnaite $\left(\mathrm{Zn}_{4} \mathrm{Al}_{2}\left(\mathrm{CO}_{3}\right)(\mathrm{OH})_{12}\left(\mathrm{H}_{2} \mathrm{O}\right)_{3}\right)$ produced within overall $1290 \mathrm{~min}(21.5 \mathrm{~h})$ lasting corrosion of the original Dev. alloy using $5 \mathrm{mM}$ BRX dissolved in aqueous $100 \mathrm{mM} \mathrm{NaOH}$ solution (Supplementary Materials Figure S1a and Table S3, Entries 5-7).

Powder XRD analyses of samples obtained from the once re-used Dev. alloy (that caused $100 \%$ conversion BRX to $4-\mathrm{HBN}$ after overnight action) show the composition of ca. $3 \% \mathrm{Al}-\mathrm{Cu}-\mathrm{Zn}$ alloy, $65 \% \mathrm{Cu}_{2} \mathrm{O}, 7 \% \mathrm{Cu}, 16 \% \mathrm{Al}-\mathrm{Zn}$ and $9 \%$ zaccagnaite (Supplementary Materials Figure S1c, Table S3, Entry 2) while the same used Dev. alloy after subsequent overnight action on $5 \mathrm{mM}$ BRX dissolved in aqueous $100 \mathrm{mM} \mathrm{NaOH}$ (afforded only $77 \%$ conversion of BRX in this third HDB step, Figure S1b, Table S3, Entry 3) contained still ca. $2 \% \mathrm{Al}-\mathrm{Cu}-\mathrm{Zn}$ alloy, $24 \% \mathrm{Cu}_{2} \mathrm{O}, 2 \% \mathrm{Cu}, 7 \%$ zaccagnaite and, in addition $65 \% \mathrm{CuO}$ as the major species.

With this information in hand, the application of some reductant in excess capable to reduce both produced copper oxides and $\mathrm{C}-\mathrm{Br}$ bonds serves as the potential technique for recycling of used Dev. alloy. Promisingly, applying of prolonged reaction times, together with the addition of external reductant $\mathrm{NaBH}_{4}$, led to the complete conversion of starting BRX to the mixture of 3-bromo-4-hydroxybenzonitrile (3-Br-4-HBN) and 4-hydroxybenzonitrile (4-HBN), even in the case of the already three-times used undissolved part of the original Dev. alloy (Figure 7, Supplementary Materials Table S4, Entries 1-3). Subsequent experiments were focused on exploring the conditions that enable the HDB of BRX. These attempts involved (i) use of different amounts of $\mathrm{NaBH}_{4}$ and (ii) changing the reaction time at room temperature (Supplementary Materials Table S4, Entries 4-6). Unfortunately, the complete HDB of BRX to 4-HBN was not achieved in these cases.

The effects of the coaction of $\mathrm{NaBH}_{4}$ and commercially available unused Dev. alloy on the HDB of BRX were investigated using different amount of both involved reduction agents. For this set of experiments, aqueous solution of $5 \mathrm{mM}$ BRX in a slightly lower excess $(20 \mathrm{mM})$ of $\mathrm{NaOH}$ was used with the aim to suppress the known stabilizing effect of $\mathrm{NaOH}$ to $\mathrm{NaBH}_{4}$. The obtained results (Supplementary Materials Table S5, Entries 1-3; 6-8) documented that a decrease in the added amount of $\mathrm{NaOH}$, along with the addition of $\mathrm{NaBH}_{4}$ to the unused Dev. alloy significantly decreases the HDB rate, together with the dissolution rate of aluminium metal. This seems to be a benefit for a potential recycling of the Dev. alloy, albeit, as demonstrated in the Table S5 (Supplementary Materials, Entry 5), the second recycling of the used Dev. alloy (even under coaction of $\mathrm{NaBH}_{4}$ ) fails in quantitative conversion of the BRX even after $68 \mathrm{~h}$ of action. Moreover, an extension of the reaction time causes subsequent reduction of the cyano group instead of the desired HDB process, which was confirmed by the NMR spectroscopy (Figures S7-S9) and GC-MS analysis (Figures S10 and S11). The HDB rate of BRX has been examined (Figure S3) based on the data obtained in these experiments. The measured data imply that the complete conversion of BRX using the Dev. alloy and $\mathrm{NaBH}_{4}$ was achieved within less than $1 \mathrm{~h}$ but the following HDB of 3-Br-4-HBN is the key rate-determining step. The changes in structure of the Dev. alloy during HDB of BRX in coaction of $\mathrm{NaBH}_{4}$ are supported by the X-ray diffractograms and SEM images in Figure 5. Comparing the XRD data of the Dev. alloy used together with $\mathrm{NaBH}_{4}$ after 2-6 h of action, decrease of content of probably most reactive $\mathrm{CuAl}_{2}$ is remarkable along with the formation of low quantities of metallic copper and $\mathrm{Cu}_{2} \mathrm{O}$, both in the form of nanoparticles. 


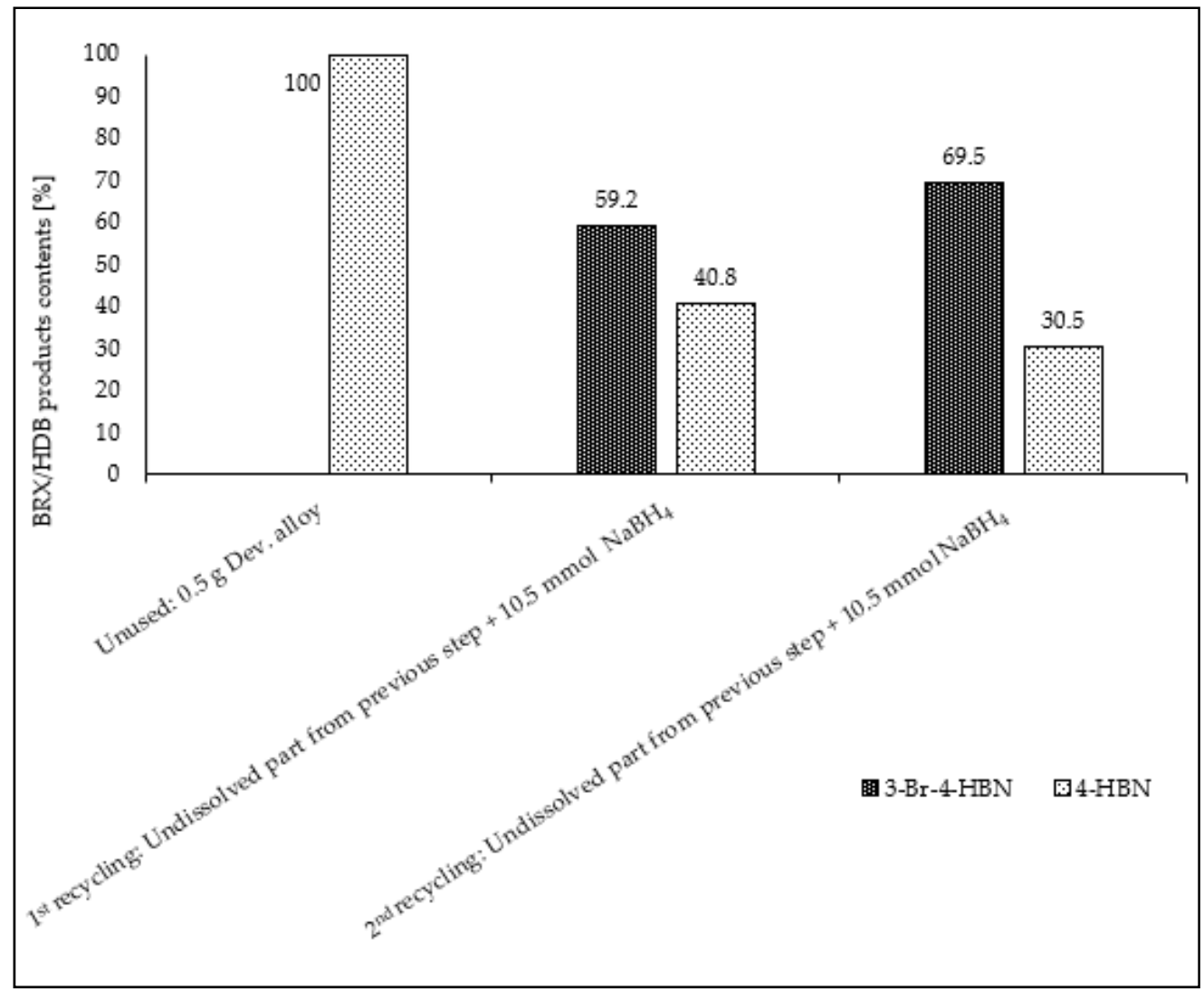

Figure 7. Effect of Dev. alloy recycling on the $\mathrm{HDB}$ of $\mathrm{BRX}$ using $\mathrm{NaBH}_{4}$ after $18 \mathrm{~h}$ of vigorous stirring. Dev. alloy was added to the solution containing $2.5 \mathrm{mmol} \mathrm{BRX}+50 \mathrm{mmol} \mathrm{NaOH}$ in $100 \mathrm{~mL} \mathrm{H}_{2} \mathrm{O}$.

In accordance with the above observed, it was found that once under a coaction of $\mathrm{NaBH}_{4}$ the used Dev. alloy in the subsequent HDB step (Supplementary Materials, Table S5, Entry 9) is only slightly less active in comparison with the unused one in excess of $\mathrm{NaOH}$ (compare with Figure 1 and Table 1, Entry 4). As we observed in the aforementioned experiments, the increase of metallic copper content in the reused spend Dev. alloy (Figures 4 and 5) caused by $\mathrm{NaBH}_{4}$-mediated in-situ reduction of $\mathrm{Cu}_{2} \mathrm{O}$ has not significant catalytic effect on the HDB process.

It was also found that pure powdered copper exhibited poor HDB activity under the coaction of $\mathrm{NaBH}_{4}$ (Supplementary Materials Table S2, Entries 4-8 and Figure S5). Employing Arnd's (Mg-Cu) alloy (Table S2, Entry 1) within the HDB of BRX provided results quite similar to the aforementioned synergistic effect of the Dev. alloy combined with $\mathrm{NaBH}_{4}$ (compare with Table S5, Entry 1 and Figure 8).

Beside the experiments described vide supra, other potential $\mathrm{Cu}$-based metal catalysts (e.g., bronze $\mathrm{Cu}-\mathrm{Sn}$, brass $\mathrm{Cu}-\mathrm{Zn}$ ) for the $\mathrm{NaBH}_{4}$ mediated $\mathrm{HDB}$ of $\mathrm{BRX}$ have been explored (Figure 9, Table S2). However, the obtained results within the respective HDB processes using brass or bronze powders (Table S2, Entries 2 and 3) are much worse when compared to the results obtained within employing the Dev. alloy. Due to the low content of Zn metal in the Dev. alloy and negligible effect of the $\mathrm{Cu}$-Zn alloy or powdered $\mathrm{Zn}$ on the HDB of $B R X$, the effect of zinc metal was neglected in proposed HDB mechanism. 


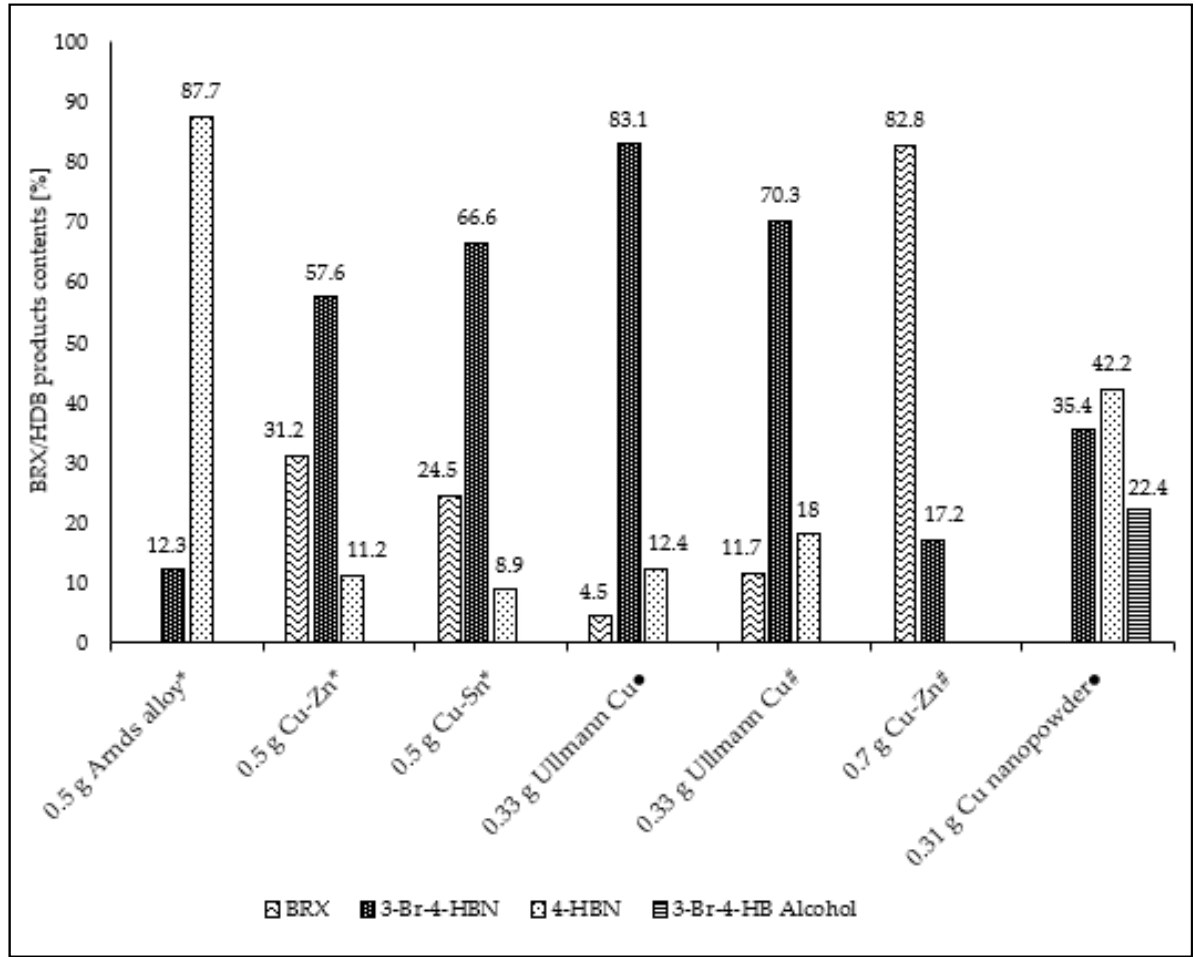

Figure 8. Effect of different sources of the Cu-catalysts on the $\mathrm{HDB}$ of $\mathrm{BRX}$ using $\mathrm{NaBH}_{4}$ after $18 \mathrm{~h}$. HDB agents were added to the solution containing $0.5 \mathrm{mmol} \mathrm{BRX}+10 \mathrm{mmol} \mathrm{NaOH}$ in $100 \mathrm{~mL} \mathrm{H}_{2} \mathrm{O}+5 \mathrm{mmol} \mathrm{NaBH}_{4}\left(^{*}\right)$ or $0.5 \mathrm{mmol} \mathrm{BRX}+2 \mathrm{mmol}$ $\mathrm{NaOH}$ in $100 \mathrm{~mL} \mathrm{H}_{2} \mathrm{O}+21 \mathrm{mmol} \mathrm{NaBH}_{4}(\bullet)$; or $0.5 \mathrm{mmol} \mathrm{BRX}$ in $100 \mathrm{~mL} \mathrm{MeOH}+21 \mathrm{mmol} \mathrm{NaBH}_{4}(\#)$.

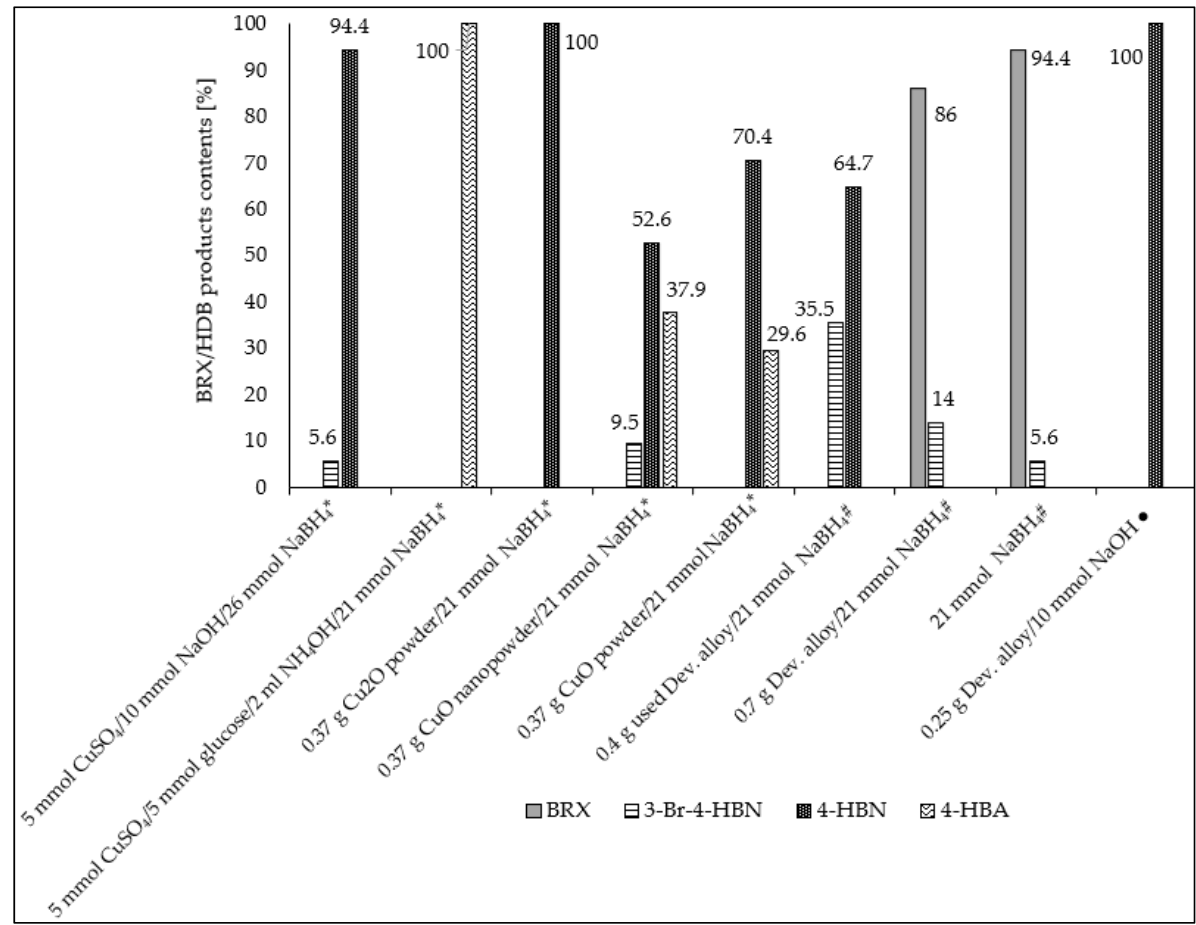

Figure 9. Effect of different sources of the $\mathrm{Cu}$-catalyst with coaction of $\mathrm{NaBH}_{4}$ on the $\mathrm{HDB}$ of $\mathrm{BRX}$ after $18 \mathrm{~h}$ of vigorous stirring. Comparison with HDB of BRX caused by the Devalloy/ $\mathrm{NaOH}$ action. HDB agents were added to the solution containing $0.5 \mathrm{mmol} \mathrm{BRX}+2 \mathrm{mmol} \mathrm{NaOH}$ in $100 \mathrm{~mL} \mathrm{H}_{2} \mathrm{O}\left(^{*}\right), 0.5 \mathrm{mmol} \mathrm{BRX}+10 \mathrm{mmol} \mathrm{NaOH}$ in $100 \mathrm{~mL} \mathrm{H} \mathrm{H}_{2} \mathrm{O}(\bullet)$ and $0.5 \mathrm{mmol} \mathrm{BRX}$ in $100 \mathrm{~mL} \mathrm{MeOH}(\#)$. 
Similarly, as in the case of the proposed mechanism of action by the Dev. alloy mediated hydrodechlorination [36], the formation of $\mathrm{Cu}_{2} \mathrm{O}$ during two-step $\mathrm{HDB}$ of $\mathrm{BRX}$ could be explained by oxidation of both $\mathrm{Cu}$ and $\mathrm{Al}$ in the starting $\mathrm{CuAl}_{2}$ (khatyrkite) with $\mathrm{BRX}$ and producing $\mathrm{CuCl}$ as an intermediate, which is hydrolyzed to $\mathrm{Cu}_{2} \mathrm{O}$ in the alkaline aqueous solution (Supplementary Materials Reaction in Scheme S1).

Except the above-mentioned facts, the crucial effect of copper-based HDB in coaction of $\mathrm{NaBH}_{4}$ is not fully clear yet.

The control set of experiments comprising addition of a $\mathrm{Cu}$ powder to the aqueous $\mathrm{NaBH}_{4}$ solution and BRX causes (after ca. 3 days) debromination of BRX to the first step but, quite unexpectedly, very slow HDB of the formed 3-Br-4-HBN intermediate which was not completed even after 96 h (Supplementary Materials Figure S5 and Table S2, Entries 4-8). On the other hand, without an employment of powdered copper, the HDB does not proceed at room temperature even after $96 \mathrm{~h}$ of $\mathrm{NaBH}_{4}$ action (Table 1, Entry 16).

The application of the commercially available $\mathrm{Cu}$ nanoparticles instead of the copper powder increase the reaction rate of $\mathrm{NaBH}_{4}$ mediated HDB (Table S2, Entries 6 and 7), which could be expected due to a much higher specific surface area. However, significant amount of a novel product, 3-bromo-4-hydroxybenzylalcohol was formed. In principle, the intermediates (i.e., 3-Br-4-HBN) formed within the described HDB process of BRX catalyzed by $\mathrm{Cu}$ nanoparticles may undergo subsequent reduction of cyano group. The by-products were identified as 3-bromo-4-hydroxybenzylalcohol (3-Br-4-HB Alcohol) and presumably 3-bromo-4-hydroxybenzaldehyde (Figures S7-S11). The proposed reaction pathway of such unexpected reduction is depicted in Scheme 3.<smiles>N#Cc1cc(O)c(O)c(Br)c1</smiles>

A) Dev.alloy/NaOH $\quad \downarrow$ G

C) $\mathrm{Cu}_{2} \mathrm{O} / \mathrm{NaBH}_{4}$

D) $\mathrm{CuSO}_{4} / \mathrm{NaBH}_{4}$

E) $\mathrm{CuO} / \mathrm{NaBH}_{4}$

F) $\mathrm{Cu} / \mathrm{NaBH}_{4}$

G) nanoCu/ $\mathrm{NaBH}_{4}$

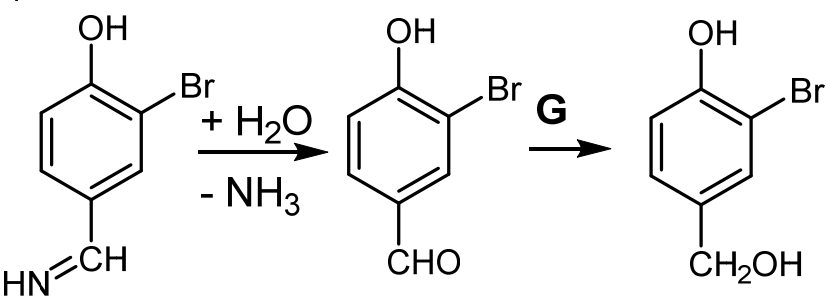

Scheme 3. Proposed reduction pathways for the studied BRX degradation.

For comparison, it was described by Raut et al. [37] that even hydrodechlorination of monochlorinated aromatic compounds in low concentration (in milligrams per liter) is possible using nanoparticles of metallic copper (1-3 g nanoCu/L) in a coaction of $\mathrm{NaBH}_{4}$ $(0.25-1.5 \mathrm{~g} / \mathrm{L})$. Our research group observed $\mathrm{Cu}$-mediated hydrodechlorination in the case of hexa- or pentachlorobenzene using the Dev. alloy [36]. However, this dechlorination was non-complete and less chlorinated benzenes (especially tetrachloro-, trichloro- and dichlorobenzenes) were produced with simultaneous formation of $\mathrm{Cu}_{2} \mathrm{O}$ and $\mathrm{Al}(\mathrm{III})$ salts (but not metallic $\mathrm{Cu}$ ).

For the elucidation of possible influence of $\mathrm{NaOH}$ on the $\mathrm{HDB}$ efficiency caused by copper or copper-based alloys-catalyzed $\mathrm{NaBH}_{4}$ action, $10 \mathrm{mM}$ methanolic solution of BRX was used instead of $5 \mathrm{mM}$ BRX solution in $20 \mathrm{mM}$ aqueous $\mathrm{NaOH}$ (Supplementary Materials, Table S2, Entries 4-5 and 8-9 and Table S7). In this case the HDB efficiency of BRX in methanolic/aqueous solution is generally considerably slower (Figures 8 and 9). 
Using $\mathrm{Cu}_{2} \mathrm{O}$ as a $\mathrm{Cu}$-based catalyst for the desired $\mathrm{NaBH}_{4}$ mediated HDB of BRX, $100 \%$ conversion of BRX to $4-\mathrm{HBN}$ was obtained after an overnight reaction (Figure 9). The HDB rate of BRX using $\mathrm{Cu}_{2} \mathrm{O} / \mathrm{NaBH}_{4}$ is depicted in Figure 10. The complete HDB reaction is accompanied by formation of mixture of metallic copper and $\mathrm{Cu}_{2} \mathrm{O}$ nanoparticles (Figures 11d and 12).

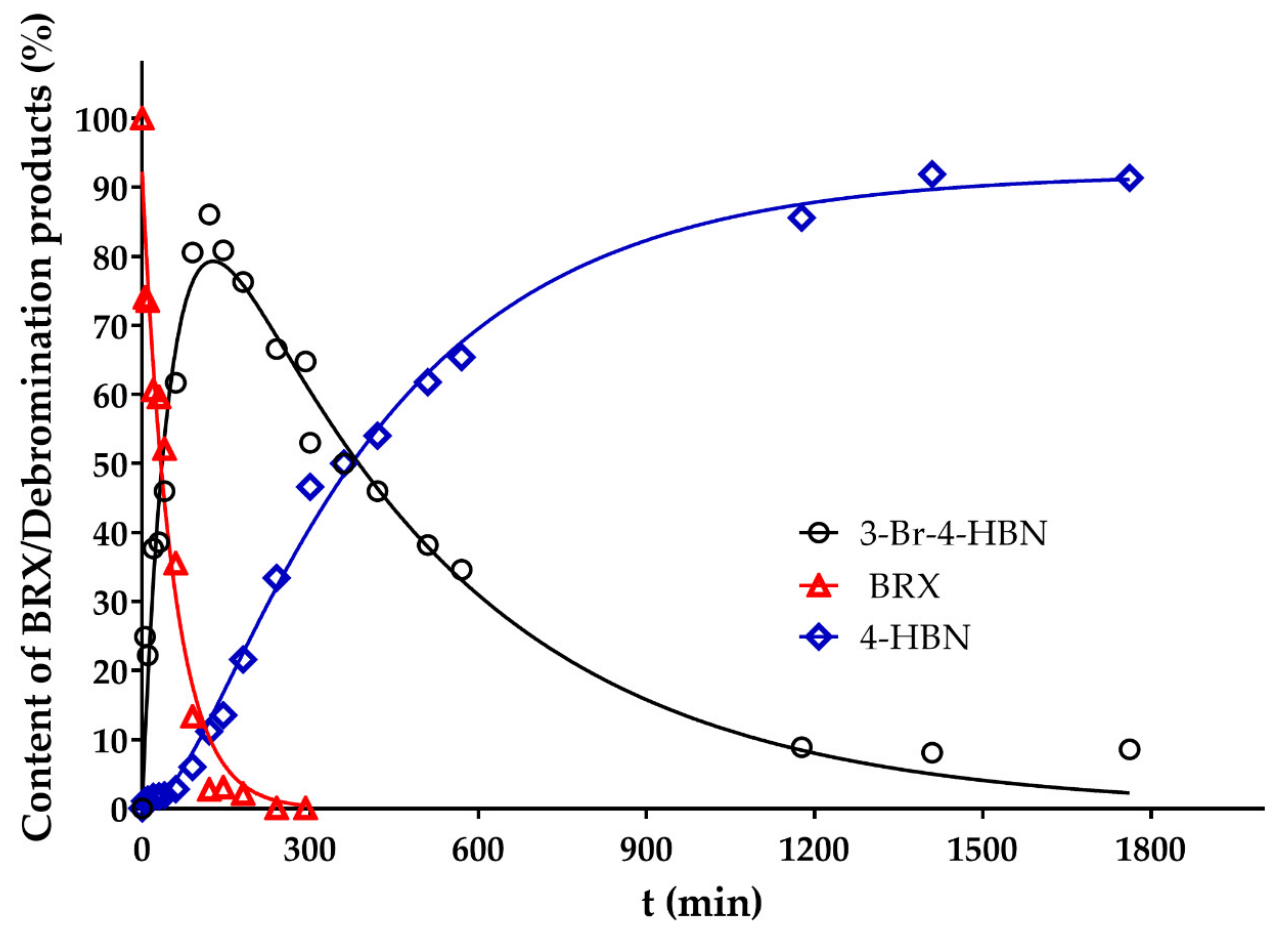

Figure 10. $\mathrm{HDB}$ rate of $5 \mathrm{mM} \mathrm{BRX}$ in $20 \mathrm{mM} \mathrm{NaOH}$ using $\mathrm{Cu}_{2} \mathrm{O}(3.1 \mathrm{~g} / \mathrm{L})$ under the coaction of $\mathrm{NaBH}_{4}(8 \mathrm{~g} / \mathrm{L})$.

Employing powdered $\mathrm{CuO}$ together with $\mathrm{NaBH}_{4}$ for the HDB of BRX, mixture of 4-HBN and 4-HBA was formed after an overnight reaction (Figure 9). Interestingly, combination of nanoparticles of $\mathrm{CuO}$ with $\mathrm{NaBH}_{4}$ is noticeably worse reducing system producing 9.5\% of the 3-Br-4-HBN intermediate together with desired 4-HBN without any positive effect of higher specific surface area of nano $\mathrm{CuO}$ on HDB (compare results obtained using micro- or nano- particles of $\mathrm{CuO}$ (Figure 9 and Supplementary Materials Table S6, Entries 9 and 10). Due to the lower selectivity and worse $\mathrm{HDB}$ activity of $\mathrm{CuO} / \mathrm{NaBH}_{4}$ compared with the Dev. alloy or $\mathrm{Cu}_{2} \mathrm{O} / \mathrm{NaBH}_{4}$ reduction systems, the $\mathrm{CuO} / \mathrm{NaBH}_{4}$ mediated $\mathrm{HDB}$ was not further investigated in details.

For comparison of the HDB activity of the tested $\mathrm{Cu}$-based reduction systems, the evaluation of kinetics of studied BRX hydrodehalogenations was performed. The calculated values of rate constants (Table 2) confirmed that only the Dev. alloy in alkaline aqueous solution exhibits high HDB activity for studied BRX at room temperature. For Dev. alloy $/ \mathrm{NaOH} / \mathrm{BRX}$, the process of 3-Br-4-HBN formation is significantly faster in comparison with $\mathrm{Cu}_{2} \mathrm{O} / \mathrm{NaBH}_{4}$ and a few orders faster in comparison with $\mathrm{Cu} / \mathrm{NaBH}_{4}$. Total HDB of BRX using the Dev. alloy in aqueous $\mathrm{NaOH}$ solution proceeding via the 3-Br-4-HBN was finished ca. in 120 min (Figure 1). The comparable values of $\mathrm{k}_{1}$ constant were obtained based on the time dependence of BRX and 3-Br-4-HBN concentration which confirmed that HDB process follows the kinetic model of subsequent reaction (Figure 1 , Scheme 1). This fact was also confirmed by high $\mathrm{R}^{2}$ values for the both reaction steps (Table 2). 


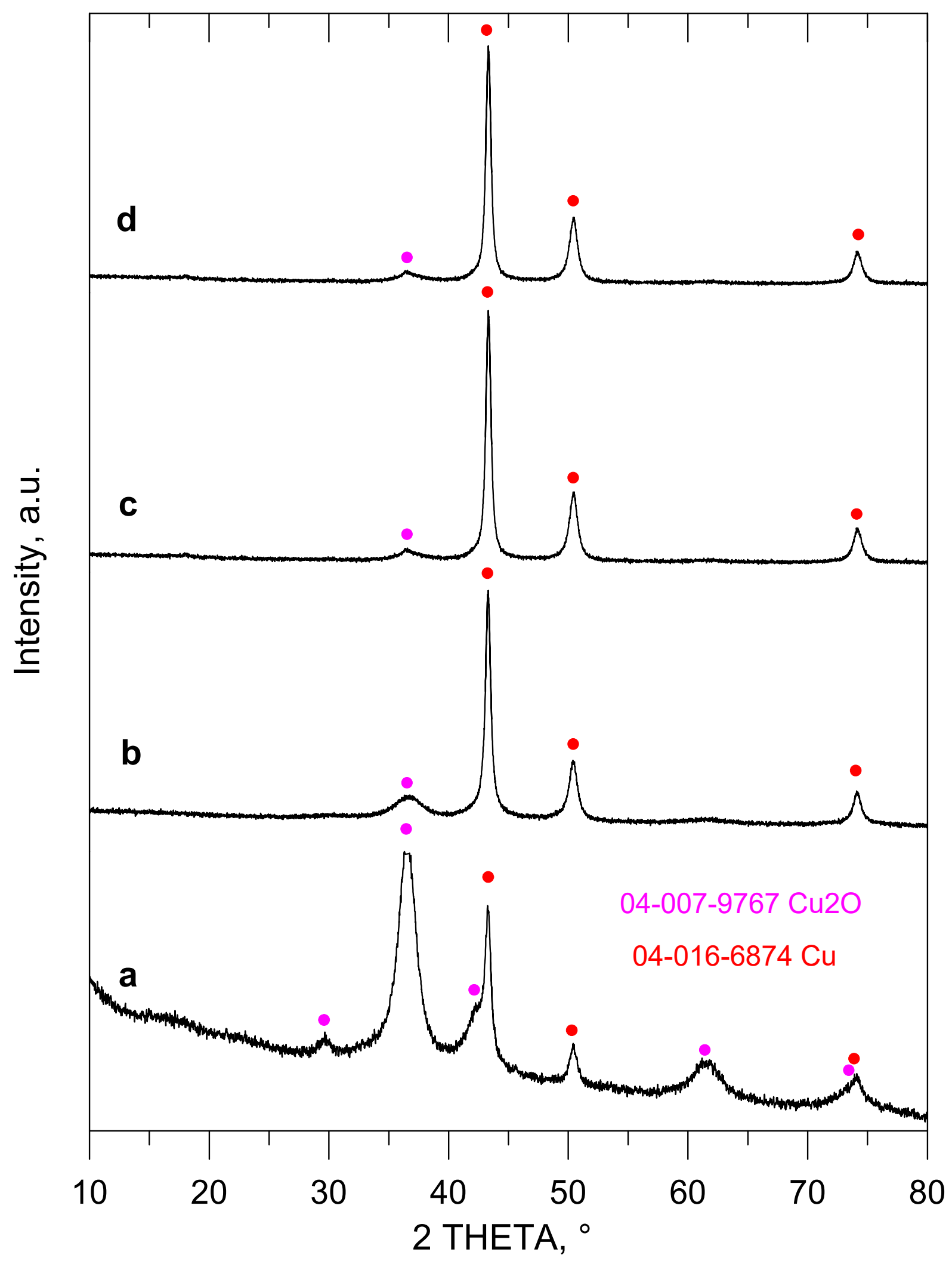

Figure 11. Powder X-ray diffractograms of insoluble part after HDB of BRX (5 mM solution in $20 \mathrm{mM}$ aq. $\mathrm{NaOH}$ ) mediated by: (a) $\mathrm{CuSO}_{4} \cdot 5 \mathrm{H}_{2} \mathrm{O}(8.33 \mathrm{~g} / \mathrm{L})+\mathrm{NaOH}(2.8 \mathrm{~g} / \mathrm{L})+\mathrm{NaBH}_{4}(6.67 \mathrm{~g} / \mathrm{L}) ;($ b $) \mathrm{CuSO}_{4} \cdot 5 \mathrm{H}_{2} \mathrm{O}(8.34 \mathrm{~g} / \mathrm{L})+\mathrm{NaOH}$ $(2.6 \mathrm{~g} / \mathrm{L})+\mathrm{NaBH}_{4}(6.67 \mathrm{~g} / \mathrm{L}) ;(\mathbf{c}) \mathrm{NaBH}_{4}(8 \mathrm{~g} / \mathrm{L})+\mathrm{CuO}$ nanopowder $(3.7 \mathrm{~g} / \mathrm{L}) ;(\mathbf{d}) \mathrm{NaBH}_{4}(8 \mathrm{~g} / \mathrm{L})+\mathrm{Cu} 2 \mathrm{O}(3.7 \mathrm{~g} / \mathrm{L})$. 

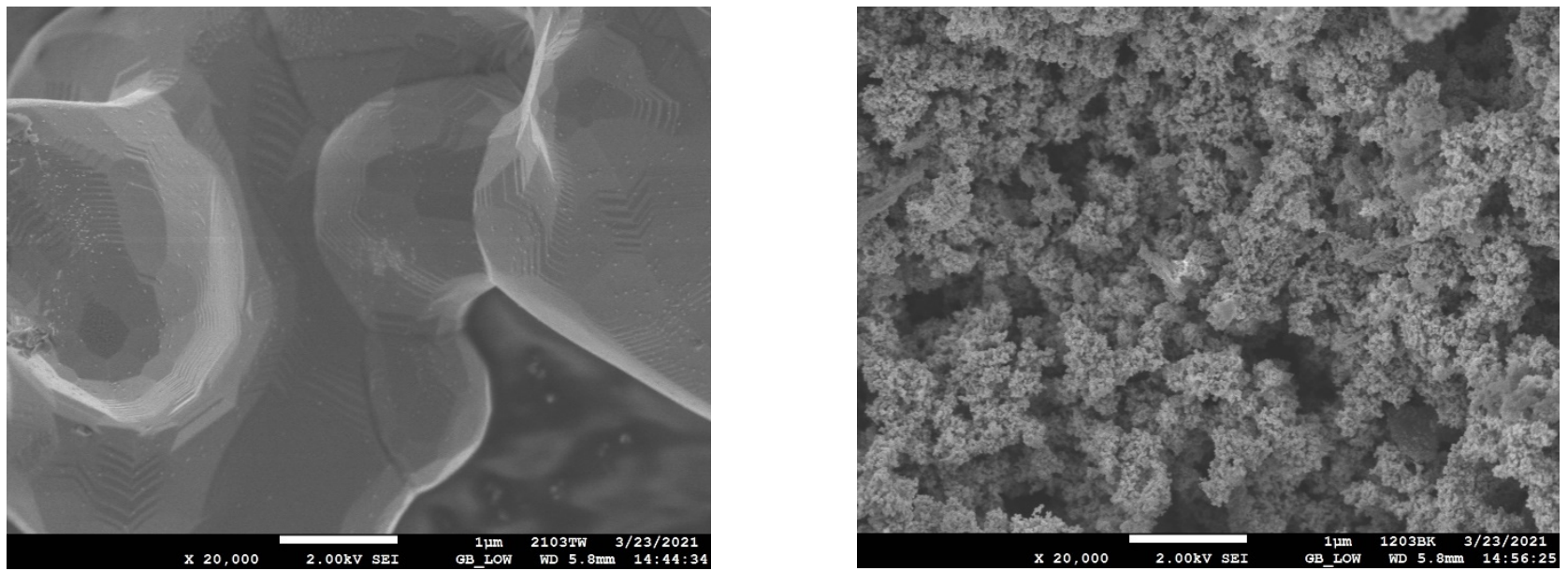

Figure 12. SEM images of the starting commercial $\mathrm{Cu}_{2} \mathrm{O}$ after the treatment of $5 \mathrm{mM} \mathrm{BRX}$ solution in $20 \mathrm{mM}$ aqueous $\mathrm{NaOH}$ without added $\mathrm{NaBH}_{4}$ (left) and separated insoluble part (mixture of $\mathrm{Cu}$ and $\mathrm{Cu}_{2} \mathrm{O}$ nanoparticles) after the HDB of BRX (5 mM BRX solution in $20 \mathrm{mM}$ aqueous $\mathrm{NaOH}$ ) using $\mathrm{Cu}_{2} \mathrm{O} / \mathrm{NaBH}_{4}$ (right).

Table 2. Calculated kinetic constants $\left(\mathrm{k}_{1}\right.$ and $\left.\mathrm{k}_{2}\right)$ for the HDB of BRX using different Cu-based HDB agents ( $\mathrm{k}_{1}$ represents the first order rate constant of the first reaction step and $k_{2}$ represents the rate constant of the second reaction step (see Scheme 1), SD is standard deviation and $\mathrm{R}^{2}$ is coefficient of determination).

\begin{tabular}{|c|c|c|c|c|}
\hline & $\mathrm{Cu} / \mathrm{NaBH}_{4}$ & $\mathrm{Cu}_{2} \mathrm{O} / \mathrm{NaBH}_{4}$ & Dev. Alloy/NaBH 4 & Dev. Alloy/NaOH \\
\hline $\begin{array}{l}\mathbf{k}_{\mathbf{1}} \pm \mathrm{SD}\left(\min ^{-1}\right) \\
\text { calculated based on the time } \\
\text { dependence of BRX }\end{array}$ & $(8.8 \pm 0.4) \times 10^{-4}$ & $0.0183 \pm 0.0018$ & $0.07277 \pm 0.0116$ & $0.150 \pm 0.0082$ \\
\hline $\begin{array}{c}\mathbf{R}^{2} \\
\mathbf{k}_{1}+\mathbf{S D}\left(\min ^{-1}\right)\end{array}$ & 0.9960 & 0.9729 & 0.9620 & 0.9942 \\
\hline $\begin{array}{l}\text { calculated based on the time } \\
\text { dependence of 3-Br-4-HBN }\end{array}$ & $(7.4 \pm 0.2) \times 10^{-4}$ & $0.0192 \pm 0.0026$ & $* 0.06864 \pm 0.0241$ & $0.1630 \pm 0.0343$ \\
\hline $\begin{array}{l}\quad \mathbf{k}_{2} \pm \mathrm{SD}\left(\mathrm{min}^{-1}\right) \\
\text { calculated based on the time } \\
\text { dependence of 3-Br-4-HBN }\end{array}$ & $(7.3 \pm 0.3) \times 10^{-5}$ & $0.00225 \pm 0.0030$ & ${ }^{*} 0.03874 \pm 0.0163$ & $0.0341 \pm 0.0047$ \\
\hline $\mathbf{R}^{2}$ & 0.9981 & 0.9565 & 0.9842 & 0.9719 \\
\hline
\end{tabular}

* calculated based on the time dependence of 4-HBN.

On the basis of the values of $\mathrm{k}_{1}$ and $\mathrm{k}_{2}$ constants (Scheme 1, Table 2), it is clear that when using $\mathrm{Cu}_{2} \mathrm{O} / \mathrm{NaBH}_{4}$, the process of 3-Br-4-HBN formation is approximately by one order slower compared to the Dev. alloy $/ \mathrm{NaOH}$, which shows lower HDB efficiency of $\mathrm{Cu}_{2} \mathrm{O} / \mathrm{NaBH}_{4}$ towards BRX (Figure 10). After $1800 \mathrm{~min}$., approximately $90 \%$ conversion of $\mathrm{BRX}$ to $4-\mathrm{HBN}$ was achieved. The HDB of BRX ( $5 \mathrm{mM}$ BRX in $20 \mathrm{mM} \mathrm{NaOH}$ ) using $\mathrm{Cu}_{2} \mathrm{O}$ under the coaction of $\mathrm{NaBH}_{4}$ also follows the kinetic model of subsequent reaction of the pseudo-first order which is presented on Figure 10 and confirmed by a compliance of $k_{1}$ values determined based on the time dependence of BRX and 3-Br-4-HBN concentration.

The HDB efficiency of $\mathrm{Cu} / \mathrm{NaBH}_{4}$ towards BRX is very low which was confirmed by the low values of $k_{1}$ and $k_{2}$ (Table 2), but the HDB process also follows the kinetic model of subsequent reaction (high value of $\mathrm{R}^{2}$; compliance of $\mathrm{k}_{1}$ values determined based on the time dependence of BRX and 3-Br-4-HBN concentration). After $72 \mathrm{~h}$, approximately $24 \%$ conversion of BRX to 4-HBN was achieved (compare Figure S5 with Figure S3).

The comparison of rate of 4-HBN formation using studied Dev. alloy/ $\mathrm{NaOH}$, Dev. alloy $/ \mathrm{NaBH}_{4}$ and $\mathrm{Cu}_{2} \mathrm{O} / \mathrm{NaBH}_{4}$ reduction systems mentioned in Table 2 is depicted in Figures 11 and S6 (reductive degradation rate of BRX). Using the Dev. alloy/ $\mathrm{NaOH}$ system, during $120 \mathrm{~min}$ of the reaction all amount of $\mathrm{BRX}$ was converted to 4-HBN. In the case of the Dev. alloy $/ \mathrm{NaBH}_{4}$ catalysts, it is about $63 \%$ and for $\mathrm{Cu}_{2} \mathrm{O} / \mathrm{NaBH}_{4}$ system the conversion (in $120 \mathrm{~min}$ ) is only $11 \%$ (Figure 13). 


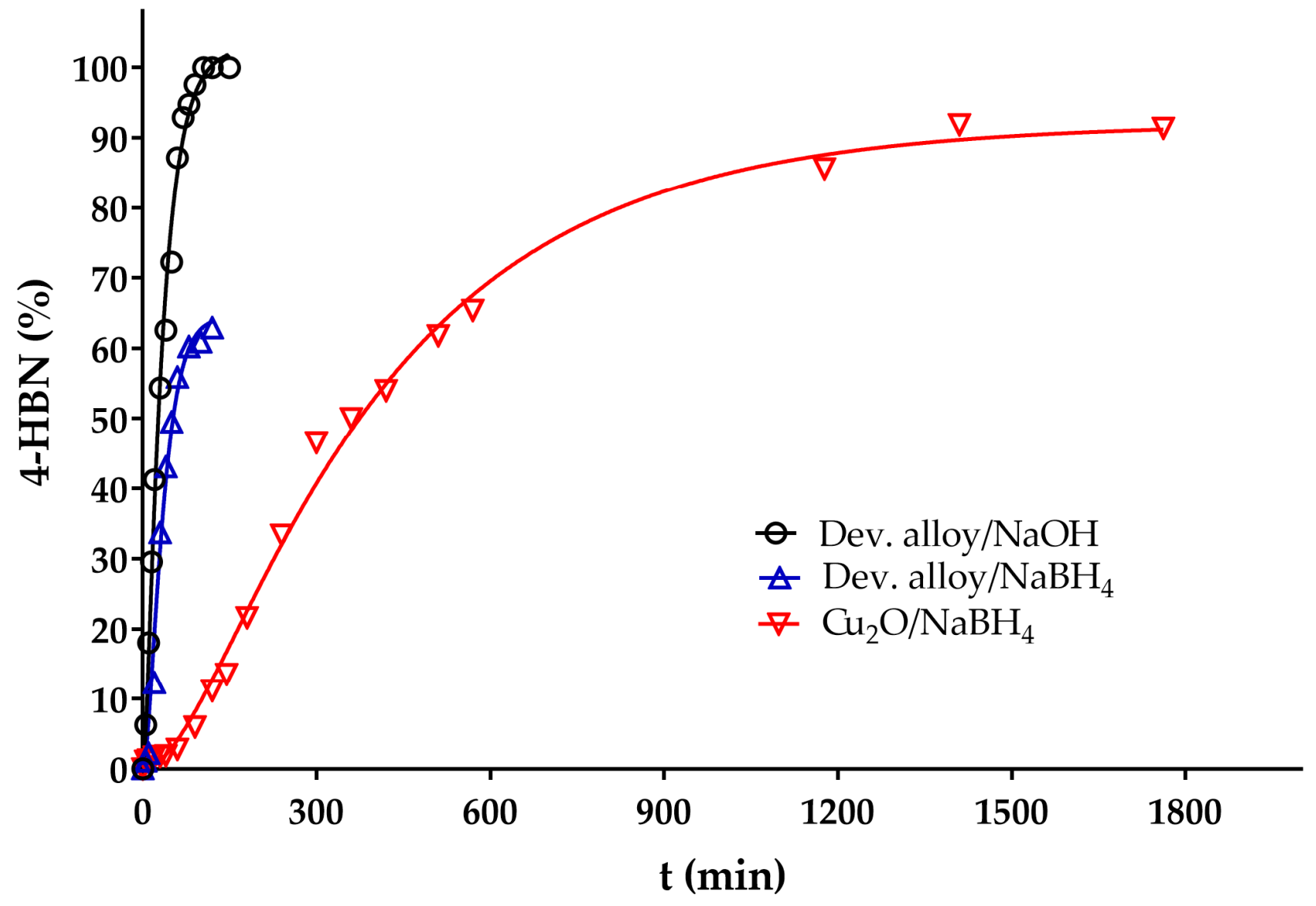

Figure 13. Time dependence of the 4-HBN formation by the HDB of BRX using different HDB systems.

Surprisingly, in-situ generation of copper/ $\mathrm{Cu}_{2} \mathrm{O}$ by the addition of aqueous solution of $\mathrm{CuSO}_{4}$ to the alkaline solution of excess of $\mathrm{NaBH}_{4}$ in aqueous BRX causes HDB process of BRX rapidly and the HDB is accompanied by the reduction of the cyano group (Supplementary Materials Table S6, Entries 2, 3, 5, 9-12 and Figures S7-S11). According to the powder $\mathrm{X}$-ray analysis, using mentioned conditions, nanoparticles of both metallic $\mathrm{Cu}$ and $\mathrm{Cu}_{2} \mathrm{O}$ are produced which significantly accelerates observed reduction processes (Figure 11a,b and Figure 14). The formation of metallic $\mathrm{Cu}(0)$ and $\mathrm{Cu}_{2} \mathrm{O}$ was also observed in both cases by $\mathrm{Cu}_{2} \mathrm{O} / \mathrm{NaBH}_{4}$ as well as by $\mathrm{CuSO}_{4} / \mathrm{NaBH}_{4}$ mediated $\mathrm{HDB}$ of BRX (Figures 11 and 14).

Taking into the account these findings, we propose the plausible reaction pathway comprising formation of $\mathrm{Cu}(\mathrm{I})$ salt of $\mathrm{BRX}\left(\mathrm{Cu}^{+} \mathrm{BRX}^{-}\right)$in the first reaction step between $\mathrm{CuOH}$ and sodium salt of $\mathrm{BRX} . \mathrm{Cu}^{+} \mathrm{BRX}^{-}$undergoes smooth reduction induced by the action of $\mathrm{NaBH}_{4}$ producing thus sodium salt of 3-Br-4-HBN in the first reduction step. The sodium salt of 3-Br-4-HBN subsequently reacts with $\mathrm{CuOH}$ producing $\mathrm{Cu}^{+}(3-\mathrm{Br}-4-\mathrm{HBN})^{-}$. Nascent $\mathrm{Cu}^{+}(3-\mathrm{Br}-4-\mathrm{HBN})^{-}$intermediate is reduced in the following HDB step to the 4HBN. Both HDB steps are accompanied by the formation of metallic copper and hydrogen (Scheme 4). 

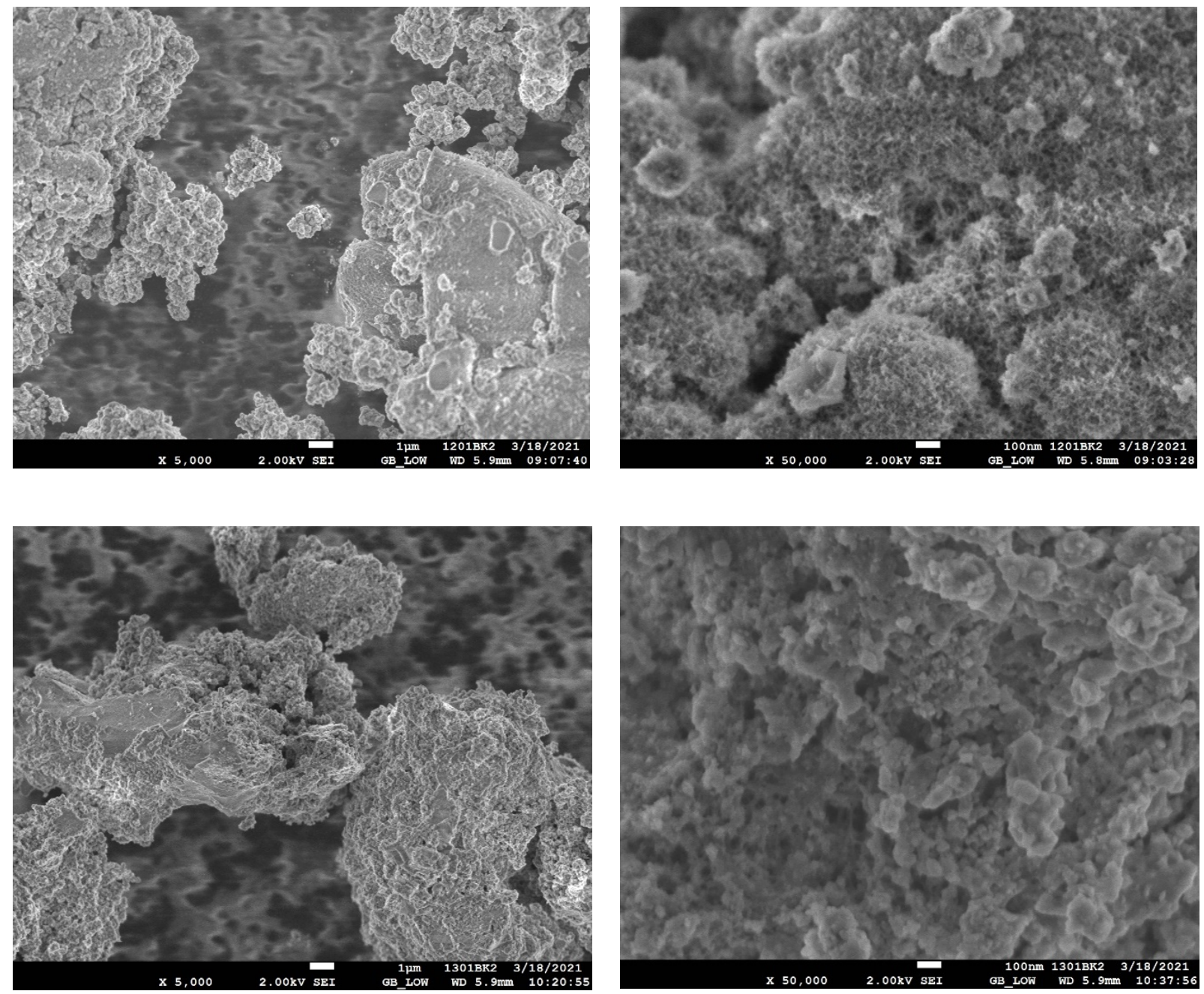

Figure 14. SEM images of the insoluble part after the treatment of $5 \mathrm{mM}$ BRX solution in $20 \mathrm{mM}$ aqueous $\mathrm{NaOH}$ with $\mathrm{NaBH}_{4} / \mathrm{CuSO}_{4}$ (top left 5000 times magnification, top right 50,000 times magnification) and with $\mathrm{CuSO}_{4} / \mathrm{NH}_{4} \mathrm{OH} /$ glucose $/ \mathrm{NaBH}_{4}$ (bottom left 5000 times magnification, bottom right 50,000 times magnification).

These findings were subsequently applied to verify the possibility of the HDB of tetrabromobisphenol A (TBBPA) which is well-known polybrominated pollutant widely used as flame retardant (Supplementary Materials Table S8, Scheme 5).

Both Dev. alloy $/ \mathrm{NaOH}$ and $\mathrm{CuSO}_{4} / \mathrm{NaBH}_{4}$ work as an effective $\mathrm{HDB}$ agent producing pure bisphenol A under optimized reaction conditions (Supplementary Materials Table S8, Entries 3 and 4). Remarkably, using higher excess of the base, the HDB of TBBPA fails probably due to the high rate of Dev. alloy corrosion accompanied only by rapid liberation of hydrogen (Supplementary Materials Table S8, Entries 1 and 2). HDB of TBBPA using the Dev. alloy $/ \mathrm{NaBH}_{4}$ is significantly slower as could be seen within a comparison with the Dev. alloy/NaOH (Table S8, Entry 5). Interestingly, metallic $\mathrm{Cu} / \mathrm{NaBH}_{4}$ is quite comparable HDB agent for TBBPA with $\mathrm{Cu}_{2} \mathrm{O} / \mathrm{NaBH}_{4}$ system (Supplementary Materials, Table S8, Entries 6 and 7). $\mathrm{NaBH}_{4}$ without any Cu-based compounds is virtually ineffective within the target debromination of TBBPA (Entry 8). 
<smiles>N#Cc1cc(Br)c(O)c(Br)c1</smiles>

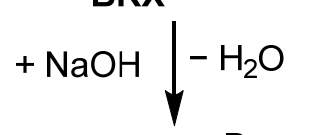

$\mathrm{Cu}_{2} \mathrm{O}+\mathrm{H}_{2} \mathrm{O} \rightleftharpoons 2 \mathrm{CuOH}$

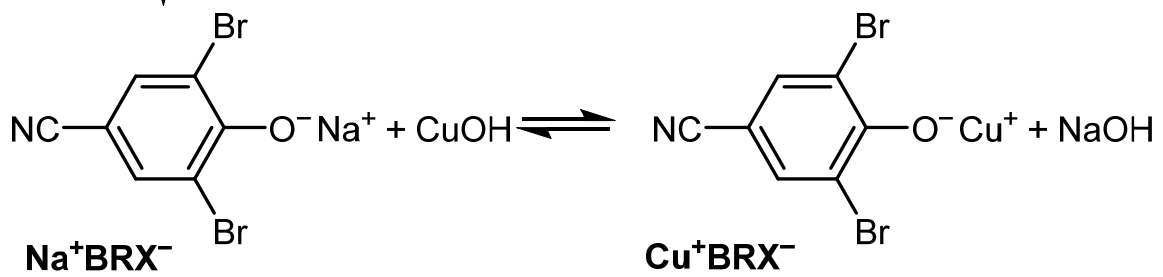

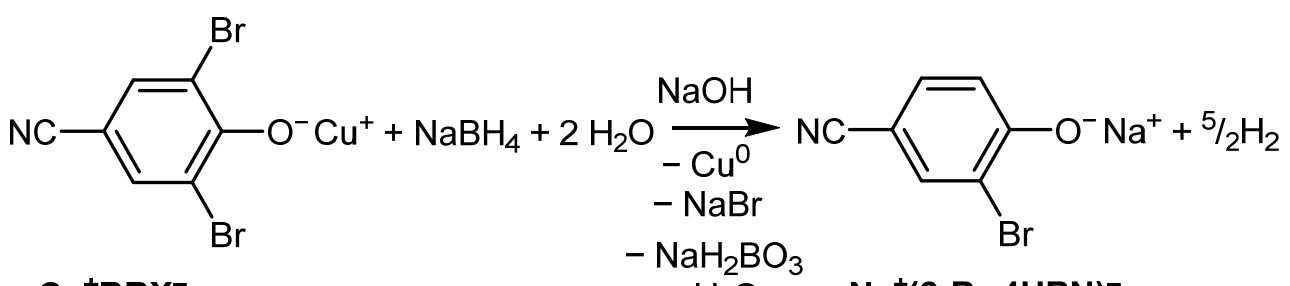

$$
\mathrm{Cu}^{+} \mathrm{BRX}^{-}-\mathrm{H}_{2} \mathrm{O} \quad \mathrm{Na}^{+}(3-\mathrm{Br}-4 \mathrm{HBN})^{-}
$$<smiles>C=CC=C[CH][NH2+]Oc1ccc(C#N)cc1Br</smiles>

$\mathrm{Na}^{+}(3-\mathrm{Br}-4 \mathrm{HBN})^{-}$

$\mathrm{Cu}^{+}(3-\mathrm{Br}-4 \mathrm{HBN})^{-}$<smiles>N#Cc1ccc([O+][C+]N[13CH2][18OH])c(Br)c1</smiles>

Scheme 4. Plausible pathway for the $\mathrm{Cu}_{2} \mathrm{O} / \mathrm{NaBH}_{4}$-based $\mathrm{HDB}$ of BRX.<smiles>[X]c1cc(C(C)(C)c2cc([X])c(O)c([X])c2)ccc1O</smiles>

Scheme 5. HDB of TBBPA using tested Cu-based reductants.

\section{Materials and Methods}

The starting brominated phenols Bromoxynil (abcr chemicals GmbH., Karlsruhe, Germany) and tetrabromobisphenol A (Alfa-Aesar Co., Thermo Fisher Scientific, Heysham, UK) were purchased from commercial sources in a defined purity higher than $95 \%$. The aluminium alloys (Devarda's Al-Cu-Zn, 45-50-5\%, p.a.; Arnd's Mg-Cu, 40-60\%; brass, $\mathrm{Cu}-\mathrm{Zn}$ powder-60 mesh; bronze, Cu-Sn spherical powder-200 mesh) and copper-based compounds $\mathrm{CuO}(\mathrm{CuO}$ nanopowder $<50 \mathrm{~nm}$ and $\mathrm{CuO}$ powder $<10 \mu \mathrm{m}, 98 \%)$, metallic $\mathrm{Cu}$ (Cu nanopowder 60-80 $\mathrm{nm}$ and $\mathrm{Cu}$ powder $<425 \mu \mathrm{m}, 99.5 \%$ ), $\mathrm{Cu}_{2} \mathrm{O}$ (powder $<99.99 \%$, 
anhydrous), $\mathrm{CuBr}_{2}(99 \%), \mathrm{NaBH}_{4}(95 \%)$ and deuterated chloroform $\left(\mathrm{CDCl}_{3}\right)$ were purchased from Sigma-Aldrich Co. (Czech Republic). The $\mathrm{Fe}_{3} \mathrm{Al}$ (97.5\%) and silver brazing alloy (1.6 mm dia, Ag:Cu:Zn 30:38:32) was purchased from Alfa-Aesar Co. (Thermo Fisher Scientific, Heysham, UK). Additional chemicals and solvents in a p.a. quality were obtained from a local supplier (Lach-Ner Co., Neratovice, Czech Republic).

The comparative experiments were performed in $250 \mathrm{~mL}$ round-bottomed flasks equipped with magnetic stirring on Starfish equipment (Radleys Discovery Technologies, Saffron Walden, UK) installed on a magnetic stirrer Heidolph Heistandard for parallel reactions. The reaction flasks were fitted by a tube filled with granulated charcoal.

\subsection{Chemical Analysis}

The ${ }^{1} \mathrm{H}$ NMR spectra were recorded from solutions in $\mathrm{CDCl}_{3}$ on a Bruker Avance 500 spectrometer (equipped with a Z-gradient $5 \mathrm{~mm}$ ProdigyTM cryoprobe) at a frequency

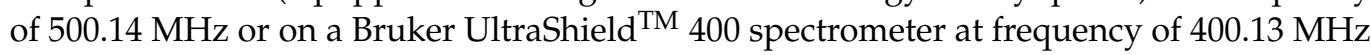
at $295 \mathrm{~K}$. The solutions were obtained by dissolving obtained evaporated residue (resulting from the work-up of reaction mixtures) in $1 \mathrm{~mL}$ of $\mathrm{CDCl}_{3}$. The values of ${ }^{1} \mathrm{H}$ chemical shifts were calibrated to the residual signals of $\mathrm{CDCl}_{3}\left(\delta\left({ }^{1} \mathrm{H}\right)=7.27 \mathrm{ppm}\right)$. The mutual content of particular constituents in obtained mixtures was established via the integration of the corresponding area resonances. The identification of respective species in prepared samples has been done accordingly to the Spectral Database for Organic Compounds [38,39] or Online NMR Database accessible free of charge [40].

The diffraction patterns $(\mathrm{Cu} \mathrm{K} \alpha, \lambda=1.5418 \AA)$ of powdered samples were recorded on a D8 Advance diffractometer (Bruker AXS, Karlsruhe, Germany) with Bragg-Brentano $\theta-\theta$ goniometer (radius $217.5 \mathrm{~mm}$ ) equipped with Ni-beta filter and LynxEye detector. The scan was performed at room temperature from $5^{\circ}$ to $80^{\circ}(2 \theta)$ in $0.01^{\circ}$ steps with a counting time of $1 \mathrm{~s}$ per step. The mass concentrations of the present phases were calculated by full pattern matching using EVA software (Bruker AXS GmbH, Karlsruhe, Germany) [34]. For each selected pattern, EVA adjusts the scaling factor and width parameters by fitting, and the result is transformed into concentrations using I/Icor factors from PDF-4+ database (Swarthmore, PA, USA) [35].

To analyze the extractable compounds in the sample of aqueous reaction solution, the extraction with $\mathrm{CH}_{2} \mathrm{Cl}_{2}$ (SupraSolv ${ }^{\circledR D C M}$ for GC/MS, Merck, USA) was performed ( $300 \mathrm{~mL}$ of waste water sample was extracted repeatedly by $3 \times 5 \mathrm{~mL}$ of $\mathrm{CH}_{2} \mathrm{Cl}_{2}$ ) with subsequent concentration of obtained dichloromethane phase to approximately $1 \mathrm{~mL} . \mathrm{CH}_{2} \mathrm{Cl}_{2}$ extract was injected in split (50:1) mode with the injector temperature set at $280^{\circ} \mathrm{C}$ and detector set at $230^{\circ} \mathrm{C}$. The extract was analyzed on 6890GC/MSD 5973 Inert (Agilent Technologies, USA) using $30 \mathrm{~m}$ capillary Agilent J\&W DB-5ms Ultra Inert column (I.D. $0.25 \mathrm{~mm}$, $0.25 \mu \mathrm{m}$ film thickness) (Agilent Technologies, USA). The temperature program started from $50{ }^{\circ} \mathrm{C}$ for $2 \mathrm{~min}$, ramp at $10^{\circ} \mathrm{C} / \mathrm{min}$ to $300{ }^{\circ} \mathrm{C}$. MS spectra were recorded using electron impact ionization (EI, $70 \mathrm{eV}$ ) in a full-scan mode.

\subsection{HDB Procedures}

3.2.1. HDB of Brominated Phenols Using Studied Al Alloys, Electropositive Metals or $\mathrm{Cu}$-Based Catalysts and $\mathrm{NaBH}_{4}$

The aqueous solution $(5 \mathrm{mM}, 100 \mathrm{~mL}$ ) of BRX dissolved in aqueous $\mathrm{NaOH}$ solution (or $10 \mathrm{mM}$ BRX solution in methanol) was mixed with Al-based alloy, electropositive metal or Cu-based catalyst (appropriate quantities are specified in Table 1 and in Supplementary Materials Tables S1-S8) and eventually other tested chemical was added slowly under vigorous stirring to the obtained suspension. The reaction mixture was stirred at $500 \mathrm{rpm}$ at $25^{\circ} \mathrm{C}$ for the appropriate time period, decanted, aqueous phase was filtered, and the filtrate was acidified to $\mathrm{pH} \sim 2.5-3$ using $16 \mathrm{wt} . \% \mathrm{H}_{2} \mathrm{SO}_{4}$ and extracted with one portion of $\mathrm{CH}_{2} \mathrm{Cl}_{2}(1 \times 100 \mathrm{~mL})$ overnight under vigorous stirring. Collected $\mathrm{CH}_{2} \mathrm{Cl}_{2}$ extract was evaporated to dryness and approximately $30 \mathrm{mg}$ of nonvolatile residue was dissolved in 
$\mathrm{CDCl}_{3} .{ }^{1} \mathrm{H}$ NMR spectrum of obtained $\mathrm{CDCl}_{3}$ solution (and eventually GC-MS) indicates the conversion of the BRX to HDB products.

\subsection{2. $\mathrm{HDB}$ of Brominated Phenols Using In Situ Generated $\mathrm{Cu} / \mathrm{Cu}_{2} \mathrm{O}$}

An appropriate quantity of $\mathrm{NaBH}_{4}$ was dissolved in the solution $(5 \mathrm{mM}, 100 \mathrm{~mL})$ of $\mathrm{BRX}$ dissolved in aqueous $\mathrm{NaOH}$ solution, and to this solution, appropriate quantity of additive and subsequently aqueous $\mathrm{CuSO}_{4}$ solution $(40 \mathrm{mM}, 50 \mathrm{~mL})$ was added dropwise under vigorous stirring (exact quantities are specified in Tables S6 and S8 in Supplementary Materials). The reaction mixture was stirred at $500 \mathrm{rpm}$ at $25^{\circ} \mathrm{C}$ overnight, filtered, acidified to $\mathrm{pH} 2.5-3$ using $16 \mathrm{wt} . \% \mathrm{H}_{2} \mathrm{SO}_{4}$ and extracted with one portion of $\mathrm{CH}_{2} \mathrm{Cl}_{2}(1 \times 100 \mathrm{~mL})$ overnight using vigorous stirring. The collected $\mathrm{CH}_{2} \mathrm{Cl}_{2}$ extract evaporated to dryness and approximately $30 \mathrm{mg}$ of nonvolatile residue was dissolved in $\mathrm{CDCl}_{3} .{ }^{1} \mathrm{H} \mathrm{NMR}$ spectrum of obtained $\mathrm{CDCl}_{3}$ solution (and eventually GC-MS) indicates the conversion of the BRX to HDB products.

For analyses of brominated compounds and products of their reduction in sample of aqueous solutions extraction with $\mathrm{CH}_{2} \mathrm{Cl}_{2}$ was performed ( $50 \mathrm{~mL}$ of aqueous phase acidified to $\mathrm{pH}=2-3$ was extracted by $50 \mathrm{~mL}$ of $\mathrm{CH}_{2} \mathrm{Cl}_{2}$ by overnight vigorous stirring) with subsequent evaporation of obtained dichloromethane phase to dryness.

\subsubsection{HDB Kinetic Experiments}

To the $500 \mathrm{~mL}$ of $5 \mathrm{mM}$ BRX solution in aqueous $\mathrm{NaOH}(100 \mathrm{mM} \mathrm{NaOH}$ using Dev. alloy or $20 \mathrm{mM} \mathrm{NaOH}$ using other reduction systems) the appropriate quantity of $\mathrm{Cu}$ based reduction agent(s) (see description in corresponding Figures captions) was added under vigorous stirring $(600 \mathrm{rpm})$. Subsequently, $50 \mathrm{~mL}$ portions of samples in appropriate time intervals were collected sequentially, filtered, filtrates were acidified to $\mathrm{pH} \sim 2.5-3$ using 16 wt. $\% \mathrm{H}_{2} \mathrm{SO}_{4}$ and extracted with $50 \mathrm{~mL}$ of $\mathrm{CH}_{2} \mathrm{Cl}_{2}$ overnight for GC-MS and/or NMR analysis.

\subsection{Evaluation of Kinetics of the HDB of BRX)}

Rate constants $\left(k_{1}\right.$ and $\left.k_{2}\right)$ of BRX debromination were evaluated based on non-linear regression analysis using GraphPad Prism 7.05 (GraphPad Software, San Diego, CA, USA). The time dependences of concentration of BRX and debromination products were fitted to the kinetic model of subsequent reaction of the first order (Figures 1, 7 and 11, Scheme 1 and Supplementary Materials Figures S3, S5 and S6) according to the equations:

$$
\begin{gathered}
c(\mathrm{BRX})=c_{0}(\mathrm{BRX}) \cdot e^{-k_{1} \cdot t} \\
c(3-\mathrm{Br}-4-\mathrm{HBN})=\frac{k_{1} \cdot c_{0}(\mathrm{BRX})}{k_{1}-k_{2}} \cdot\left(e^{-k_{2} t}-e^{-k_{1} t}\right)
\end{gathered}
$$

where $c(\mathrm{BRX})$ and $c(3-\mathrm{Br}-4-\mathrm{HBN})$ are the actual concentrations of $\mathrm{BRX}$ and 3-Br-4$\mathrm{HBN}$ in time $t, c_{0}(\mathrm{BRX})$ is the initial concentration of $\mathrm{BRX}, k_{1}$ and $k_{2}$ are the rate constants of the first and second reaction step.

The value of $k_{1}$ corresponding to the first step of subsequent reaction (the formation of 3-Br-4-HBN) was evaluated based on the time dependence of BRX concentration and compared with the value of $k_{1}$ calculated from the time dependence of 3-Br-4-HBN. The value of $k_{2}$ rate constant can be also evaluated based on the time dependence of 4-HBN concentration but this possibility was not used due to the difficulties with subsequent reaction of 4-HBN (which undergoes subsequent transformation to 4-HBA). Coefficient determination $\left(R^{2}\right)$ and absolute sum of squares of residues were chosen as a criterion for assessing of quality of the fit.

\section{Conclusions}

To conclude, it was found that among the tested $\mathrm{Cu}$-based agents and/or catalysts for the HDB of studied BRX (e.g., brass Cu-Zn, bronze Cu-Sn, Devarda's Al-Cu-Zn alloy with 
coaction of $\mathrm{NaOH}$ or $\mathrm{NaBH}_{4}, \mathrm{Cu} / \mathrm{NaBH}_{4}, \mathrm{Cu}_{2} \mathrm{O} / \mathrm{NaBH}_{4}, \mathrm{CuO} / \mathrm{NaBH}_{4}$ ), the best efficiency is achieved by the Dev. alloy in alkaline aqueous solution. The major drawback of this HDB reagent is its poor direct reusability due to the rapid and significant loss of the desired catalytic HDB activity. The main reason for this behavior is presumably the decrease in active $\mathrm{CuAl}_{2}$ content during the HDB process in alkaline aqueous solution accompanied by the structural changes within the catalytically active $\mathrm{Cu}$-species of the used Dev. alloy (i.e., formation of $\mathrm{Cu}_{2} \mathrm{O}$, zaccagnaite and other $\mathrm{Al}(\mathrm{III})$ compounds).

The possibility of addition of $\mathrm{NaBH}_{4}$ as a replacement agent of consumed aluminium from the used Dev. alloy was investigated as well. The results are at least indicative of the possible employment of the used Dev. alloy $/ \mathrm{NaBH}_{4}$ mixture for partial HDB of starting $\mathrm{BRX}$; however, such modified HDB process has never reached the desired completion.

We have also demonstrated that cooperative action of the Dev. alloy $/ \mathrm{NaBH}_{4}$ mixture of reagents within the HDB of alkaline BRX solution somewhat decrease the consumption of crucial aluminium bound within the Dev. alloy. Due to this reason, such cooperative action causes much slower HDB reaction rate and provides the same disadvantage resulting in a non-complete HDB process leading only to the formation of the 3-Br-4-HBN in case of attempted reuse of the partially spent Dev. alloy.

As one of the most interesting result, we have found that the $\mathrm{Cu}$-based alloys are able of mediating the cyano group reductions in aqueous solutions at ambient temperature. To the best of our knowledge, such finding has not been described in the literature so far.

Finally, the possibility of employing the most promising HDB agent, the Dev. alloy with coaction of $\mathrm{NaOH}$, has been auspiciously investigated within the environmentally desirable HDB processes of industrially important brominated flame retardant TBBPA, too.

Interestingly, though the Dev. alloy is not recyclable directly in studied HDB process, the in-situ formation of mixed $\mathrm{Cu}(0) / \mathrm{Cu}_{2} \mathrm{O}$ nanoparticles in coaction of $\mathrm{NaBH}_{4}$ enables effective and complete HDB of both studied BRX and TBBPA (Scheme 6).

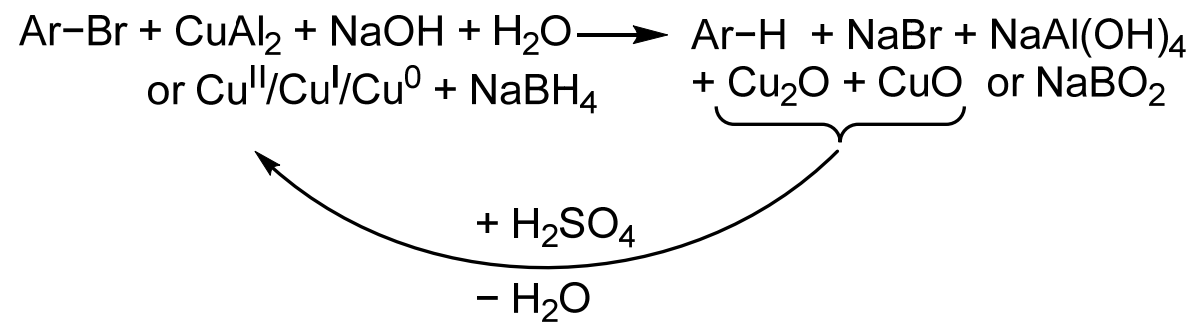

Scheme 6. Proposed sustainable method for studied Cu-based HDB of Ar-Br.

Based on new findings described in this article, for the complete HDB of both studied BRX and TBBPA, either the Dev. alloy in the coaction of excess of $\mathrm{NaOH}$ or combination of soluble $\mathrm{Cu}(\mathrm{II})$ salt under excess of $\mathrm{NaBH}_{4}$ are the only efficient HDB agents. Due to this reason, for sustainability of the proposed HDB process based on $\mathrm{NaBH}_{4}$, the crucial hydrometallurgical treatment of spent $\mathrm{Cu}$ catalyst (i.e., Dev. alloy, eventually $\mathrm{Cu}_{2} \mathrm{O}$ or $\mathrm{CuO}$, Scheme 6) with $\mathrm{H}_{2} \mathrm{SO}_{4}$ or $\mathrm{HCl}[33]$ is required.

Supplementary Materials: The following are available online at https: / www.mdpi.com/article / 10.3390 / catal11060699/s1, Table S1: Effect of $\mathrm{Cu}^{0}, \mathrm{CuBr}_{2}$ and $\mathrm{Cu}(\mathrm{I})$ or $\mathrm{Cu}(\mathrm{II})$ oxides on $0.5 \mathrm{mmol}$ BRX dissolved in $0.1 \mathrm{~L}$ of $0.1 \mathrm{M} \mathrm{NaOH}$; Table S2: Effect of different sources of copper on the HDB of BRX under the coaction of $\mathrm{NaBH}_{4}$; Table S3: Recyclability experiments of the Dev. alloy within the HDB of BRX; Table S4: Recyclability experiments of the used Dev. alloy under the coaction of $\mathrm{NaBH}_{4}$; Table S5: Recyclability of Dev. alloy used under the coaction of $\mathrm{NaBH}_{4}$; Table S6: Effect of different sources of copper on the HDB of BRX under the coaction of $\mathrm{NaBH}_{4}$; Table S7: Effect of different sources of copper on the HDB of BRX in aq./methanolic solution without excess of $\mathrm{NaOH}$; Table S8: HDB of TBBPA after overnight reaction using different HDB agents. Figure S1: Powder X-ray diffractograms of undissolved residues of reused Dev. alloys; Figure S2: Effect of repeated application of Dev. alloy in the coaction of $\mathrm{NaBH}_{4}$; Figure S3:HDB rate of $5 \mathrm{mM}$ aq. BRX dissolved in $20 \mathrm{mM} \mathrm{NaOH}$ mediated by the Dev. alloy $(7.1 \mathrm{~g} / \mathrm{L})$ under the coaction of $\mathrm{NaBH}_{4}(8 \mathrm{~g} / \mathrm{L})$; 
Figure S4: Effect of added $\mathrm{NaOH}$ on the $\mathrm{HDB}$ of $\mathrm{BRX}$ after $18 \mathrm{~h}$ of vigorous stirring; Figure S5: HDB rate of $5 \mathrm{mM}$ aq. BRX dissolved in $20 \mathrm{mM}$ aq. $\mathrm{NaOH}$ using powdered copper $(3.4 \mathrm{~g} / \mathrm{L})$ and under the coaction of $\mathrm{NaBH}_{4}(8 \mathrm{~g} / \mathrm{L})$; Figure S6: Comparison of reductive degradation rates of BRX in aqueous $\mathrm{NaOH}$ using Dev. alloy or $\mathrm{Cu}_{2} \mathrm{O} / \mathrm{NaBH}_{4}$; Figure S7: Comparison of the ${ }^{1} \mathrm{H}$ NMR spectra of evaporated residue of $\mathrm{CH}_{2} \mathrm{Cl}_{2}$ extracts obtained after the reaction of $5 \mathrm{mM} \mathrm{BRX}$ in aqueous $\mathrm{NaOH}$ with $\mathrm{Cu}^{0} / \mathrm{NaBH}_{4}$ (top), excess of Dev. alloy (middle) and nano $\mathrm{Cu}^{0} / \mathrm{NaBH}_{4}$ (bottom); Figure S8: Comparison of the ${ }^{1} \mathrm{H}$ NMR spectra (details of aromatic regions) of evaporated residue of $\mathrm{CH}_{2} \mathrm{Cl}_{2}$ extracts obtained after the reaction of $5 \mathrm{mM} \mathrm{BRX}$ in aqueous $\mathrm{NaOH}$ with $\mathrm{Cu}^{0} / \mathrm{NaBH}_{4}$ (top), excess of Dev. alloy (middle) and nanoCu ${ }^{0} / \mathrm{NaBH}_{4}$ (bottom); Figure S9: Comparison of the ${ }^{1} \mathrm{H}$ NMR spectra (details of aromatic regions) of evaporated residue of $\mathrm{CH}_{2} \mathrm{Cl}_{2}$ extracts obtained after the reaction of $5 \mathrm{mM} \mathrm{BRX}$ in aqueous $\mathrm{NaOH}$ with $\mathrm{Cu}^{0} / \mathrm{NaBH}_{4}$ (top), excess of Dev. alloy (middle) and nano $\mathrm{Cu}^{0} / \mathrm{NaBH}_{4}$ (bottom); Figure S10: GC-MS analysis of $\mathrm{CDCl}_{3}$ extract of reaction mixture obtained after $\mathrm{HDB}$ of $5 \mathrm{mM}$ BRX dissolved in $20 \mathrm{mM} \mathrm{NaOH}$ using nano $\mathrm{Cu} / \mathrm{NaBH}_{4}$ (Table S2, Entry 7) (retention times are given in minutes); Figure S11. (a) GC chromatogram of GC-MS analysis of $\mathrm{CDCl}_{3}$ extract of reaction mixture obtained after reduction of BRX by in-situ prepared nano $\mathrm{Cu}+\mathrm{NaBH}_{4}$ (Table S6, Entry 12) (retention times are given in minutes). Figure S12: GC-MS analysis of $\mathrm{CH}_{2} \mathrm{Cl}_{2}$ extract of reaction mixture described in Table S8, Entry 2, HDB of TBBPA (retention times are given in minutes); Figure S13: GC chromatogram of GC-MS analysis of DCM extract of reaction mixture after complete debromination (using Dev. alloy/ $\mathrm{NaOH}$ or $\mathrm{CuSO}_{4} / \mathrm{NaBH}_{4}$ ), Table S8, Entries 4, 5; Scheme S1: Proposed HDB of BRX using Dev. alloy and aqueous $\mathrm{NaOH}$ solution.

Author Contributions: T.W. conceived, designed and performed part of the experiments and wrote the paper; B.K. performed the experiments; L.B. performed powder X-ray measurements and analyzed the data; V.Č. performed SEM measurements; A.K. performed kinetic evaluations; J.Č. performed GC-MS measurements and analyzed the data; P.Š. performed NMR measurements. All authors have read and agreed to the published version of the manuscript.

Funding: This research was funded by Faculty of Chemical Technology, University of Pardubice, within support of excellent research.

Data Availability Statement: Data is contained within the article or supplementary material. The data presented in this study are available in [insert article or Supplementary Material here].

Acknowledgments: This work was funded by the Faculty of Chemical Technology, University of Pardubice within the financial support of excellent teams and the Technological Agency of the Czech Republic, project No.: TG02010058/GAMA2-01/005. V.C. wants to thank for financial support to the Ministry of Education, Youth and Sports of the Czech Republic (CZ.02.1.01/0.0/0.0/17_048/0007421, LM2018103).

Conflicts of Interest: The authors declare no conflict of interest.

\section{References}

1. Hao, W.; Liu, Y. C-H bond halogenation catalyzed or mediated by copper: An overview. Beilstein J. Org. Chem. 2015, 11, 2132-2144. [CrossRef] [PubMed]

2. Petrone, D.A.; Ye, J.; Lautens, M. Modern transition-metal-catalyzed carbon-halogen bond formation. Chem. Rev. 2016, 116, 8003-8104. [CrossRef]

3. Yasamut, K.; Jongcharoenkamol, J.; Ruchirawat, S.; Ploypradith, P. A modified $\mathrm{Cu}(0)-\mathrm{Cu}(\mathrm{I})$-mediated $\mathrm{C}_{\text {aryl }}-\mathrm{C}_{\text {aryl }}$ Ullmann coupling for the synthesis of biaryls. Tetrahedron 2016, 72, 5994-6000. [CrossRef]

4. Li, Y.; Han, D.; Arai, Y.; Fu, X.; Li, X.; Huang, W. Kinetics and mechanisms of debromination of tetrabromobisphenol A by Cu coated nano zerovalent iron. Chem. Eng. J. 2019, 373, 95-103. [CrossRef]

5. Weidlich, T. The influence of copper on halogenation/dehalogenation reactions of aromatic compounds and its role in the destruction of polyhalogenated aromatic contaminants. Catalysts 2021, 11, 378. [CrossRef]

6. Alaee, M.; Arias, P.; Sjodin, A.; Bergman, A. An overview of commercially used brominated flame retardants, their applications, their use patterns in different countries/regions and possible modes of release. Environ. Int. 2003, 29, 683-689. [CrossRef]

7. Müller, F.; Applebyki, A.P. Weed Control, 2. Individual Herbicides. In Ullmann's Encyclopedia of Industrial Chemistry; Wiley-WCH: Weinheim, Germany, 2012; Volume 39, pp. 209-385.

8. Shaw, S.D.; Blum, A.; Weber, R.; Kannan, K.; Rich, D.; Lucas, D.; Koshland, C.P.; Dobraca, D.; Hanson, S.; Birnbaum, L.S. Halogenated flame retardants: Do the fire safety benefits justify the risks? Rev. Environ. Health 2010, 25, 261-305. [CrossRef] 
9. Arena, M.; Auteri, D.; Barmaz, S.; Bellisai, G.; Brancato, A.; Brocca, D.; Bura, L.; Byers, H.; Chiusolo, A.; Marques, D.C.; et al. Peer review of the pesticide risk assessment of the active substance bromoxynil (variant evaluated bromoxynil octanoate). J. EFSA 2017, 15, 24.

10. Holtze, M.S.; Sørensen, S.R.; Sørensen, J.; Aamand, J. Microbial degradation of benzonitrile herbicides dichlobenil, bromoxynil and ioxynil in soil and subsurface environments-insights into degradation pathways, persistent metabolites and involved degrader organisms. Environ. Pollut. 2008, 154, 155-168. [CrossRef] [PubMed]

11. Knossow, N.; Siebner, H.; Bernstein, A. Isotope analysis method for the herbicide bromoxynil and its application to study photo-degradation processes. J. Hazard. Mater. 2020, 388, 122036. [CrossRef]

12. Palma, P.; Kuster, M.; Alvarenga, P.; Palma, V.L.; Fernandes, R.M.; Soares, A.M.V.M.; de Alda, M.J.L.; Barcelo, D.; Barbosa, I.R. Risk assessment of representative and priority pesticides, in surface water of the Alqueva reservoir (South of Portugal) using on-line solid phase extraction-liquid chromatography-tandem mass spectrometry. Environ. Int. 2009, 35, 545-551. [CrossRef]

13. Maddila, S.; Lavanya, P.; Jonnalagadda, S.B. Degradation, mineralization of bromoxynil pesticide by heterogeneous photocatalytic ozonation. J. Ind. Eng. Chem. 2015, 24, 333-341. [CrossRef]

14. Huang, Z.; Deng, D.; Qiao, J.; Ju, Y.; Chen, Y.; Dionysiou, D.D. New insight into the cosolvent effect on the degradation of tetrabromobisphenol A (TBBPA) over millimeter-scale palladised sponge iron (Pd-s-Fe0) particles. Chem. Eng. J. 2019, 361, 1423-1436. [CrossRef]

15. Iordache, I.; Wilson, S.; Lundanes, E.; Iordache, M.; Pavel, V.L.; Aelenei, N. The Fenton and sono-Fenton processes applied for pesticide degradation. Environ. Eng. Manag. J. 2010, 9, 519-525. [CrossRef]

16. Chelme-Ayala, P.; El-Din, M.G.; Smith, D.W. Degradation of bromoxynil and trifluralin in natural water by direct photolysis and UV plus $\mathrm{H}_{2} \mathrm{O}_{2}$ advanced oxidation process. Water Res. 2010, 44, 2221-2228. [CrossRef]

17. Chelme-Ayala, P.; El-Din, M.G.; Smith, D.W. Kinetics and mechanism of the degradation of two pesticides in aqueous solutions by ozonation. Chemosphere 2010, 78, 557-562. [CrossRef]

18. Bououden, Z.; Halladja, S.; Sleiman, M.; Leremboure, M.; Richard, C. Mechanism of bromoxynil phototransformation: Effect of medium and surfactant. J. Photochem. Photobiol. A Chem. 2018, 365, 151-156. [CrossRef]

19. Horikoshi, S.; Miura, T.; Kajitani, M.; Horikoshi, N.; Serpone, N. Photodegradation of tetrahalobisphenol-A (X=Cl, Br) flame retardants and delineation of factors affecting the process. Appl. Catal. B 2008, 84, 797-802. [CrossRef]

20. Zhong, Y.; Liang, X.; Zhong, Y.; Zhu, J.; Zhu, S.; Yuan, P.; He, H.; Zhang, J. Heterogeneous UV/Fenton degradation of TBBPA catalyzed by titanomagnetite: Catalyst characterization, performance and degradation products. Water Res. 2012, 46, 4633-4644. [CrossRef] [PubMed]

21. Sandhiya, L.; Senthilkumar, K. Reaction mechanism and kinetics of the degradation of bromoxynil initiated by OH radical. RSC Adv. 2014, 4, 7749. [CrossRef]

22. Yang, L.; Liu, G.; Shen, J.; Wang, M.; Yang, Q.; Zheng, M. Environmental characteristics and formations of polybrominated dibenzo-p-dioxins and dibenzofurans. Environ. Int. 2021, 152, 106450. [CrossRef] [PubMed]

23. Schouttete, K.V.K.M.; Hennebel, T.; Dheere, E.; Bertelkamp, C.; De Ridder, D.J.; Maes, S.; Chys, M.; Van Hulle, S.W.H.; Vanden Bussche, J.; Vanhaecke, L.; et al. Effect of oxidation and catalytic reduction of trace organic contaminants on their activated carbon adsorption. Chemosphere 2016, 165, 191-201. [CrossRef]

24. Ma, X.X.; Liu, Y.; Li, X.Q.; Xu, J.G.; Gu, G.D.; Xia, C.H. Water: The most effective solvent for liquid-phase hydrodechlorination of chlorophenols over Raney Ni catalyst. Appl. Catal. B 2015, 165, 351-359. [CrossRef]

25. Weidlich, T.; Prokes, L.; Pospisilova, D. Debromination of 2,4,6-tribromophenol coupled with biodegradation. Centr. Eur. J. Chem. 2013, 11, 979-987. [CrossRef]

26. Weidlich, T.; Krejčová, A.; Prokeš, L. Hydrodebromination of 2,4,6-tribromophenol in aqueous solution using Devarda's alloy. Monatsh. Chem. 2013, 144, 155-162. [CrossRef]

27. Li, H.; Wang, J.; Wang, R.; Huang, K.; Luo, W.; Tao, X.; Dang, Z.; Yin, H.; Guo, C.; Lu, G. Debromination of 2,2' $4,44^{\prime}-$ tetrabromodiphenyl ether (BDE-47) by synthetic $\mathrm{Pd} / \mathrm{Fe}^{0}$ and $\mathrm{Cu} / \mathrm{Fe}^{0}$ in different protic solvents. Chemosphere 2018, 212, 946-953. [CrossRef] [PubMed]

28. Wang, R.; Tang, T.; Lu, G.; Zheng, Z.; Huang, K.; Li, H.; Tao, X.; Yin, H.; Shi, Z.; Lin, Z.; et al. Mechanisms and pathways of debromination of polybrominated diphenyl ethers (PBDEs) in various nano-zerovalent iron-based bimetallic systems. Sci. Total Environ. 2019, 661, 18-26. [CrossRef]

29. Fang, L.; Liu, R.; Xu, L.; Li, J.; Huang, L.-Z.; Li, F. Enhanced debromination of tetrabromobisphenol a by zero-valent copper nanoparticle-modified green rusts. Environ. Sci. Nano 2019, 6, 970-980. [CrossRef]

30. Durante, C.; Isse, A.A.; Todesco, F.; Gennaro, A. Electrocatalytic Activation of Aromatic Carbon-Bromine Bonds toward Carboxylation at Silver and Copper Cathodes. J. Electrochem. Soc. 2013, 160, G3073-G3079. [CrossRef]

31. Mouselmani, R.; Hachem, A.; Alaaeddine, A.; Métay, E.; Lemaire, M. Reduction of aromatic nitriles into aldehydes using calcium hypophosphite and a nickel precursor. Org. Biomol. Chem. 2018, 16, 6600-6605. [CrossRef] [PubMed]

32. Lichtenecker, R.J. Synthesis of aromatic ${ }^{13} \mathrm{C} /{ }^{2} \mathrm{H}-\alpha$-ketoacid precursors to be used in selective phenylalanine and tyrosine protein labelling. Org. Biomol. Chem. 2014, 12, 7551-7560. [CrossRef]

33. Weidlich, T.; Kamenická, B. Recycling of spent hydrodehalogenation catalysts_Problems dealing with separation of aluminium. Inz. Mineral. J. Pol. Mineral. Eng. Soc. 2019, 1, 177-182. [CrossRef]

34. Bruker AXS GmbH. Diffracplus Basic Evaluating Package. In EVA, 19th ed.; Bruker AXS GmbH: Karlsruhe, Germany, 2013. 
35. Joint Committee on Powder Diffraction Standards. PDF-4+ Database; International Centre of Diffraction Data: Swarthmore, PA, USA

36. Weidlich, T.; Kamenicka, B.; Melanova, K.; Cicmancova, V.; Komersova, A.; Cermak, J. Hydrodechlorination of different chloroaromatic compounds at room temperature and ambient pressure-Differences in reactivity of $\mathrm{Cu}$ - and $\mathrm{Ni}$-based $\mathrm{Al}$ alloys in an alkaline aqueous solution. Catalysts 2020, 10, 994. [CrossRef]

37. Raut, S.S.; Kamble, S.P.; Kulkarni, P.S. Efficacy of zero-valent copper $\left(\mathrm{Cu}^{0}\right)$ nanoparticles and reducing agent for dechlorination of mono chloroaromatics. Chemosphere 2016, 159, 359-366. [CrossRef] [PubMed]

38. SDBSWeb. National Institute of Advanced Industrial Science and Technology. Available online: https://sdbs.db.aist.go.jp (accessed on 14 April 2021).

39. Pouchert, C.J.; Behnke, J. The Aldrich Library of 13 C and 1 H FT NMR Spectra, 1st ed.; Aldrich Chemical Company, Inc.: St. Louis, MO, USA, 1993; Volume 1-3.

40. Reich, H.J. Online NMR Database Accessible Free of Charge. Available online: http://www.chem.wisc.edu/areas/organic/ index-chem.htm (accessed on 14 April 2021). 